University of Zurich

Department of Economics

Working Paper Series

ISSN 1664-7041 (print)

ISSN 1664-705X (online)

Working Paper No. 174

\title{
Analyzing educational achievement differences between second-generation immigrants: Comparing Germany and German-speaking Switzerland
}

Johannes S. Kunz

September 2014 


\title{
Analyzing educational achievement differences between second-generation immigrants: Comparing Germany and German-speaking Switzerland*
}

\author{
JOHANNES S. KUnZ ${ }^{\dagger}$ \\ University of Zurich, Department of Economics
}

August 22, 2014

\begin{abstract}
In this study, I provide evidence that the educational achievement of second-generation immigrants in German-speaking Switzerland is greater than in Germany. The impact of the first-generation immigrants' destination decision on their offspring's educational achievement seems to be much more important than has been recognized by the existing literature. I identify the test score gap between these students that cannot be explained by differences in individual and family characteristics. Moreover, I show how this gap evolves over the test score distribution and how the least favorably-endowed students fare. My results suggest that the educational system of Switzerland, relative to the German system, enhances the performance of immigrants' children substantially. This disparity is largest when conditioning on the language spoken at home, and prevails even when comparing only students whose parents migrated from the same country of origin.
\end{abstract}

Keywords: Immigrant comparison; Educational achievement decomposition; Germany and Switzerland;

JEL classification: I21; I24; J15;

*I thank the editor, Michael Lechner, two anonymous referees, Gregori Baetschmann, Christian Dustmann, Winfried Pohlmeier, Philippe Ruh, Ruben Seiberlich, Florian Schaffner, Kevin Staub, Raphael Studer, Steven Stillman, Rainer Winkelmann, and seminar participants at Luzern, Zermatt, Zurich, the 'Education and Equality of Opportunity' Workshop at the ZEW, Mannheim, and the 'Junior Economist Workshop on Migration Research' at the ifoCEMIR/CESifo institute, Munich for very helpful comments and suggestions, and Daniel Auer for very helpful research assistance.

${ }^{\dagger}$ Zürichbergstrasse 14, CH-8032 Zürich, +41(0)44 63423 12, johannes.kunz@econ.uzh.ch 


\section{Introduction}

This study contributes to a growing body of literature evaluating the educational performance of children born to first-generation immigrants in Western European countries (inter alia, Algan et al., 2010; Belzil and Poinas, 2010; Dustmann, Frattini and Lanzara, 2012; Heath, Rothon and Kilpi, 2008; Lüdemann and Schwerdt, 2012; Schneeweis, 2011; Song, 2011). The literature has documented severe disadvantages faced by second-generation immigrants in terms of educational achievement, wage income, and unemployment probabilities relative to their host countries' native peers. In addition to these relative assessments, I will argue that absolute achievement and learning processes of second-generation immigrants need to receive greater attention. Focusing on second-generation immigrant students alone helps to answer the question of what the parental sorting decision implies for the educational opportunities of their children. Likewise, it indicates the effectiveness of the host countries' educational institutions in accommodating the needs of immigrants' children. Understanding their absolute learning process can help policy makers to turn their immigrant populations into a productive strength in society.

The economics of education literature has concentrated on integration by assessing withincountry educational differences between children of natives and first-generation immigrants. These relative within-country differences are then compared across countries. Conditioning on individual and family background, native-immigrant achievement gaps are reduced significantly but remain at high levels in most Western European countries. However, this approach cannot reveal the relevant parameters of the immigrant children's learning process due to the following reasons: First, imagine a family deciding upon a destination country, the relevant counterfactual is what would be the educational achievement of their offspring had they decided for another country, not had they been native parents in the chosen destination. Second, from the reduction in native-immigrant achievement differences alone it cannot be concluded that the performance of these immigrants' children is satisfactory. Instead the reduction of the performance gap might be entirely due to conditional changes in performance of natives' children. Moreover, when conditioning on the educational background of the parent population, these educational backgrounds have to be comparable across heterogeneous home countries to be meaningful. It is possible, if not probable, that having received secondary education in Turkey 
captures a different proficiency level than having completed the same education in Germany. Additionally, the covariate cells for native students with parents that have no primary education are empty or nearly empty in most developed countries. The variable language spoken at home - which has recently gained prominence in native-immigrant comparisons - is most problematic in this regard; we do not know to whom we compare the immigrants' children, and what these conditional differences tell us. Third, little is known about which educational institutions support the absolute performance of second-generation immigrants in Western European countries. Assessing language acquisition using a non-integration based approach seems to be most fruitful, since this learning process differs between immigrants' and natives' children.

Using the Programme for International Student Assessment (PISA) 2009 survey, I compare second-generation immigrant students' reading test scores directly across countries. Large scale and internationally comparable performance tests like PISA facilitate comparisons of students' educational achievement across countries. A drawback of these large-scale student evaluations in assessing second-generation immigrants is missing information on pre-migration characteristics of the parent generation, such as the reason for or the time of migration. Self-selection and self-sorting of migrants to host countries create heterogeneous immigrant populations across countries. To account for this selectivity without observing pre-migration characteristics, I focus on Germany and the German-speaking part of Switzerland. Comparing these two regions has several advantages in dealing with potential self-selection and self-sorting of first-generation immigrants: First, both countries are high immigration countries that have experienced a similar migration history, resulting in relatively homogeneous immigrant populations (Castles, 1986), which allows for an assessment of the country of origin. This is important when the human capital of the parents differs by their country of origin. Second, because they are in a similar language area, the results will be confounded neither by language differences nor by self-selection of immigrants into a certain language environment. Third, comparing countries with the same test language allows for a meaningful assessment of differences in reading literacy. Being a measure of language acquisition, it is highly relevant for the immigrants' children assimilation and learning processes.

The key contribution of this study is the comparison of reading literacy between immigrants' children in Germany and German-speaking Switzerland. First, I show that second-generation 
immigrant-native gaps diminish in both countries when conditioning on parental background characteristics, as commonly found in previous studies. Next, I decompose the achievement difference between second-generation immigrant students in Germany and German-speaking Switzerland into a component attributable to differences in background characteristics and a component that cannot be explained by those characteristics. ${ }^{1}$ The decomposition into explained and unexplained components is performed parametrically and semi-parametrically to allow for non-linear impacts of the background characteristics and failures in the out-of-support validity. Then, I show how the unexplained gap evolves over the test score distribution, and provide evidence separately for unfavorably endowed children of immigrants, Turkish descendants the largest overlapping immigrant population, and native students for reasons of comparability. Finally, I present how the gap varies with school characteristics that might support the immigrants' children learning process.

The results suggest that the performance of immigrants' children in Switzerland is substantially higher than in Germany. This disparity is largest for very low-performing and unfavorably endowed second-generation immigrants. Differences reduce but prevail when conditioning on the parents' country of origin and when restricting attention to Turkish descendants. By contrast, the improvement in educational achievement does not extend to children of native-born parents, as they score almost as well in Germany as in German-speaking Switzerland. Among several school characteristics one that seems to explain a large part of the disparity between immigrants' children is the average test score performance of pupils in school.

The remainder of this article proceeds as follows: In the next section, I discuss the literature, historical patterns of migration into Germany and Switzerland, and their educational systems; Section 3 describes the PISA 2009 dataset, covariates used, and the econometric procedure; Section 4 presents the results and a suggestive discussion on possible reasons for the difference in educational achievement; and Section 5 concludes. $^{2}$

\footnotetext{
${ }^{1}$ Due to the missing information on pre-migration characteristics, the resulting differences are interpreted as decompositions rather than causal effects. Another reason for the decomposition interpretation is that there is no obvious manipulable policy action, as discussed by Fortin, Lemieux and Firpo (2011).

${ }^{2}$ There are three appendices in the Supplementary Material: Appendix A replicates the analysis using math literacy as the outcome variable; Appendix B presents robustness checks for all language areas of Switzerland, all immigrants in both countries, sampling weights, different matching estimators, plausible values, and different imputation procedures; and Appendix $\mathrm{C}$ presents information about the sample selection, missing values/imputation, common support, and covariate balance before and after matching.
} 


\section{Literature, migration history, and school systems}

First, I highlight the present article's approach in comparison to those pursued in the literature. Subsequently, I briefly summarize the migration policies and histories of the two countries to motivate the sample of comparison, and discuss their educational systems.

\subsection{Previous literature}

The economic literature on educational achievement of second-generation immigrants in Western Europe - based on internationally comparable performance tests - focuses predominantly on integration. In these studies, integration is taken to be the difference in test score performances of immigrants' children and their host countries' native peers; cross-country studies then compare these national gaps across countries. The most detailed study has been performed by Dustmann, Frattini and Lanzara (2012). In their study, the PISA 2006 survey is used to analyze test score disparities between second-generation immigrant and native students across a large number of countries. They find that within-country gaps reduce substantially when taking into account the intergenerational correlation, as proxied by parental education levels. For Germany and Switzerland, their analysis reveals that even after conditioning on the children's family background, the gap in Germany is double the size of the gap in Switzerland.

In this study, I compare these second-generation immigrant students directly, instead of comparing their within-country immigrant-native test score gaps. This comparison has two advantages: First, within-country immigrant-native comparisons are problematic, since it is not clear whether differences originate from differential performance among the children of natives, immigrants, or both. Moreover, comparing the educational achievement of natives to that of second-generation immigrants, even when conditioning on parental education, might be misleading. For example, if receiving primary education in Turkey is different - in terms of knowledge acquisition - from primary education in Germany or Switzerland and if the intergenerational correlation in education operates through knowledge transmission, then conditioning on parental education will not reveal the effect of the destination country's school system upon immigrant children. Additionally, some covariate cells are empty and out-of-support validity is at least dubious. For example, in industrialized countries the category no primary education for native parents is almost empty as a result of compulsory schooling laws. A related problem 
arises when conditioning on the language spoken at home, a procedure that traditionally reduces the second-generation immigrant-native gap significantly. By this conditioning it is not clear to whom we compare these immigrant students, or what the conditional correlations tell us.

Second, related but different is the question whether educational researchers and policy makers shall concentrate on relative or absolute performance. In other words, how to weight the educational equity-efficiency trade-off when focusing on immigrants' children. Here, I do not aim to take a general stand on this subject. Generally, each comparison is interesting in its own right. Comparisons to natives' children can, for example, answer questions about discrimination, which the literature has documented in some detail. On the other hand, comparing immigrants with immigrants (in different countries) can identify which institutions support the immigrant students' learning process, in particular, when their learning process is different from the one of natives' children as in (second-)language acquisition. Complementing the literature by this non-integration based measure is the central motivation of this study.

So far, little is known about which educational institutions promote the second-generation immigrants' learning process, in an absolute sense, irrespective of their native peers. A notable exception is Levels, Dronkers and Kraaykamp (2008), who compare second-generation immigrants' performance directly. By pooling destination countries, their study precludes a detailed comparison across individual countries. Schnepf (2008) studies countries separately by comparing educational inequalities using the dispersion between the 5th and the 95th percentile of the test score distribution within countries. She finds that both Switzerland and Germany have a 10-20\% larger dispersion within the performance of second-generation immigrants than within natives. Schnepf (2008) argues that liberal migration policies in Western Europe created heterogeneous populations of first-generation immigrants within countries, which led to substantial inequality among their children through intergenerational transmission. Her study highlights the importance of accounting for the heterogeneity among immigrants' children within countries by looking at the distribution of test scores.

This study also fits into a developing branch of the literature that introduces new reference groups in order to assess selectivity or origin effects. Dronkers and Heus (2010) investigate negative selection of immigrants by studying their difference from non-emigrant peers. Dustmann, Frattini and Lanzara $(2012,170)$ address "the opportunities or disadvantages migration 
implies for the children of immigrants" by comparing children of Turkish immigrants to their peers who have not emigrated, and thus were born and raised in Turkey. Country of origin effects are assessed within a single destination country (e.g., Luthra, 2010; Ours and Veenman, 2003) or a single country of origin in different destination countries, again relative to the host countries' native peers (e.g. Song, 2011). My study adds to this new branch of the literature by including those whose parents have emigrated to different destination countries. This is an important reference group, because it reveals the consequences implied by the parental sorting decision. Moreover, this study includes a larger number of countries as sources of immigration, as well as a cross-country dimension.

\subsection{Migration history}

When comparing second-generation immigrant students across countries it is essential to find suitable comparison groups. Unfortunately, internationally comparable student assessments do not contain information on pre-migration characteristics of the foreign-born parents and across countries it is hard to find overlapping immigrant populations, especially when considering the country of origin. Therefore, I compare Germany and German-speaking Switzerland as they attracted very similar immigrant populations due to their migration policy regimes and language environments. In the following, I briefly summarize the relevant migration histories until 1994 when the second-generation immigrants are born (within the countries of testing). ${ }^{3}$

After the Second World War, war losses and post-war reconstruction lead to a substantial under-supply of un- and semi-skilled labor in Western Europe. The employment-to-population ratio was further diminished by low birth rates, extended compulsory education, and increasing life expectancies. Industrial expansion and new methods of mass production created an extensive demand for labor migration into Western Europe (Castles, 1986).

In 1948, Switzerland established large-scale imports of labor based on bilateral agreements with Italy, followed by Germany in 1955 (Liebig, 2004). According to Hansen (2003), recruitment in Southern Europe was due to the expectation of a smoother assimilation into the labor market compared to more distant areas or ethnicities. Both countries then started to recruit in Spain and Greece - in reaction to increasing competition for cheap labor and exhaustion of

\footnotetext{
${ }^{3}$ This section summarizes the overview of Castles (1986) and draws from Schmid (1983), Liebig (2004), and Zimmermann (1995).
} 
Southern European labor resources - they turned to Turkey, Morocco, Portugal, Tunisia, and Yugoslavia.

In Switzerland, employers recruited for themselves, but admission and organization was centralized by the Swiss government. The German government created a state recruitment administration, controlled by the Federal Labor Office. Employers had to apply for foreign labor and the Federal Labor Office set up recruitment offices in Mediterranean countries to select suitable workers. Complex legal and administrative frameworks were put in place to regulate and control foreign labor, aiming to prevent settlement by maintaining rapid turnover, a common feature of all European guest-worker programs (Castles, 1986).

By the sixties, international competition and employers' requests for a more stable workforce induced the governments of Switzerland and Germany to liberalize foreign labor policies. This initiated the phase of family migration, which allowed workers to reunify with their families. In 1963, Switzerland introduced a ceiling on the stock of foreigners per firm, which was rather unrestrictive and therefore replaced by global quotas in 1970 (Liebig, 2004, 164). These quotas set an upper limit to newly entering labor migrants into the country. In the wake of the oil crisis in 1973, the guest-worker systems came to a halt in all European countries.

In the 1980s, the ban of recruitment left family migration and later the asylum migration as the only channels to legally enter the German or Swiss labor markets. Conversely to the expected return migration, only a few of the former guest-workers returned to their home countries. ${ }^{4}$ Most had settled and could not be expelled. Asylum migration became substantial after 1989. First, the fall of the Iron Curtain led to large inflows of Eastern Europeans. Second, the Balkan war pushed many Yugoslavian refugees and asylum-seekers into Western Europe (Hansen, 2003; Algan et al., 2010).

In 1991 both countries reorganized their labor migration. In Germany, nationals of countries that were not part of the European Economic Community or some other exceptions were only allowed to fill vacancies in sectors with unmet labor demand. The Swiss government introduced the Three-Circles-Model. The first cycle granted preferential status for nationals from the European Economic Area, in the second cycle immigrants from the United States, Canada, Australia, and New Zealand could be recruited if demand could not be met within the first

\footnotetext{
${ }^{4}$ In 1983, Germany offered financial incentives for voluntary repatriation, but only a few immigrants responded to the policy.
} 
cycle, and the third cycle included nationals from all other countries who could only be recruited on a subsidiary basis (Liebig, 2004).

Overall, these patterns of migration were similar in both countries and resulted in homogenous immigrant populations (at least relative to other country pairs). ${ }^{5}$ Nevertheless, despite the similarities, there are some notable differences in the immigrant populations of Germany and German-speaking Switzerland: First, the reintegration of ethnic Germans - called Aussiedler - from Poland and the Former Soviet Union is only observed in Germany. Second, Western European (from Germany, France, or Lichtenstein) and Albanian immigrants are only observed in Switzerland. These groups could possibly have had other reasons to migrate than guestworkers and their relatives. Hence, I exclude these three categories as they have no equivalent in the other country. ${ }^{6}$ Students descending from other countries overlap. Although there are more immigrants descending from former Yugoslavia in Switzerland than in Germany, and the reverse pattern for immigrants from Turkey, their compositions will be balanced by the estimation procedure explained below.

Restricting the comparison countries to the same language area accounts for several selection aspects, such as language preferences. Yet, it is important to keep in mind, that the every-day spoken language in German-speaking Switzerland is Swiss German (a variety of dialects) which is not fully equivalent to Standard German. Nevertheless, in school children learn the written language Swiss Standard German, which is similar in most respects to Standard German. This should favor the children of immigrants in Germany, since they are exposed to Standard German not only in school but also in every-day spoken language.

\subsection{Educational systems}

In both counties, the educational systems are decentrally governed and organized by federal states: 16 "Bundesländer" in Germany and 26 "Kantone" in Switzerland. PISA assesses 15-year olds, hence participants of the 2009 wave were born between 1993 and 1994 in the respective country of testing. In this section, I briefly summarize the main features of the educational

\footnotetext{
${ }^{5}$ In the literature, it is common to contrast the German or Swiss experience with countries that have very different immigration policies such as traditional countries of migration like Canada or Australia (Entorf and Minoiu, 2005) or the United Kingdom and France (Algan et al., 2010).

${ }^{6}$ The sample proportions before and after exclusion can be found in Appendix C. I present the main results including these three groups of immigrants in Appendix B, Table B.2; the effects are similar to the preferred specification.
} 
systems within this time period. Table 1 presents some key indicators of the school systems based on the sample of immigrant students used throughout the study (and explained in Section $3.1)$.

[Table 1 about here.]

Within the children's first three years of life parents had optional access to early childhood care in both countries. From age three to six, children can visit a type of preschool called Kindergarten. In the PISA 2009 survey $92.38 \%$ of the immigrants' children in Germany and $98.77 \%$ in German-speaking Switzerland report that they have attended at least one year of Kindergarten. In Table 1, the average time spent in preschool is slightly longer in Switzerland. Despite the focus on second-language acquisition due to the different dialects in Switzerland, there were no country-wide institutional arrangements on how to support non-German-speaking children of immigrants. Every Kanton developed its own institutions of which most offered courses in German as a second-language already in Kindergarten (EDK, 2002). Similarly, there was no unified approach to support immigrants' children in Germany. Governed by the federal states, attention was paid on the testing of German language skills before entering primary school. Children identified with poor language skills were offered courses in German as a second language (KB, 2006).

In both countries, compulsory primary education starts with the sixth birthday with cut-off dates ranging from $30^{\text {th }}$ of June to $30^{\text {th }}$ of September in Germany and, with rare exceptions, form $30^{\text {th }}$ April to $30^{\text {th }}$ June in Switzerland. Hence, the effective range of school entrance ages lies between late five years and early seven years of age. In the sample, the average age at school entry is 6.40 in Germany and 6.69 in German-speaking Switzerland.

Tracking is generally organized similar and takes place early on in the children's school career. In Germany, tracking occurs after 4 years of school (with the exceptions of Berlin and Brandenburg that track in sixth grade). Generally in Switzerland tracking takes place later, after 5 to 6 years (and rare exceptions in fourth grade). In both countries, tracking is mainly based on teacher recommendations and grades in primary school. In both countries, there is some evidence for discrimination between immigrants' and natives' children at the transition from primary to secondary school (see Lüdemann and Schwerdt (2012) for Germany and Häberlin, Imdorf and Kronig (2004) for Switzerland). 
At the time of testing, when the children are at the age of 15 (or early 16), the majority of second-generation immigrant children is attending grade nine (56.47\% in Germany and $66.87 \%$ in Switzerland). The average grade level of 15-year olds is 8.97 in Germany, and 8.80 in German-speaking Switzerland. Both countries have fairly high rates of grade repetition. The probability of repeating one or more grades is 34\% in Germany and 30\% in German-speaking Switzerland (where the probability for repeating more than one grade is small, approximately $4 \%$ in Germany and 1\% in Switzerland).

In the discussion of the results below, I address some aspects of the school systems that might cause differential performance of immigrants' children in the two countries. In particular, I consider the amount of German lessons (per week), as well as the overall amount of lessons (per week), the proportion of second-generation immigrants in school, and the average performance among fellow immigrants' and natives' children in school.

It is important to note that there might be other explanations instead of the educational systems that might cause a disparity in performance between the two countries, such as attitudes towards immigrants or integration efforts in general. Yet, Mayda (2006) suggests that attitudes towards immigrants are similar and Liebig (2004) argues for parallels in integration efforts. Still, children of immigrants may perceive their inclusion into the host society differently and expect for example greater returns to education in Switzerland than in Germany. This might create incentives to invest in education and knowledge acquisition that in turn result in higher test scores. Another explanation could be that the Swiss educational system simply better fits the test. Yet, PISA evaluates "skills for life" that capture what is considered to be necessary knowledge independently of the student's curricula and that appear to be of particular importance for students with a migration background who need at the very least be able to actively participate in their host societies. In addition, it could be that intrinsic motivation to perform well on a test is different between the two groups (e.g., Segal, 2012). However, this too can be considered as an important skill that is relevant for later performance in life. If it is also resulting from the new environment it could be argued that it should be part of the achievement difference. 


\section{Data, estimation strategy, and interpretation}

In this section, I present the PISA 2009 survey, the sample selection process, and the background characteristics. Subsequently, I describe the parametric decomposition developed by Blinder (1973) - Oaxaca (1973) [henceforth BO] and the semi-parametric propensity score matching decomposition.

\subsection{Data}

A comprehensive summary of the PISA dataset is given in OECD (2009); here, I briefly summarize the features relevant for my analysis. PISA is an internationally standardized achievement test with mean (of 500) and standard deviation (of 100), facilitating an interpretation in terms of percentage points of the international standard deviation. The target population is 15-year olds enrolled in school. PISA evaluates the students' "knowledge and skills for life" in three categories: Reading, math, and science literacy. I concentrate the discussion on reading literacy results, since I believe that reading literacy and language acquisition are integral parts of the immigrants' assimilation and learning processes. ${ }^{7}$ Due to difference in every-day spoken language - German compared to Swiss German - the results might differ depending on the competences considered. I therefore included the results based on math literacy test scores in Appendix A of the Supplementary Material. The results are qualitatively the same, though the differences are larger in magnitude and of greater statistical significance.

Similar to Dustmann, Frattini and Lanzara (2012), I define second-generation immigrants as being born in the country of testing while having both parents born in a foreign country. This definition excludes children with one foreign and one native-born parent, as they are found to be statistically different from children that have both parents born in a foreign country (Ohinata and van Ours, 2012).

Ammermüller, Heijke and Wößmann (2005) note that missing information on students' background characteristics mainly stem from low-performing students, and is thus not missing at random but shall be imputed. Accordingly, I perform median imputations on the school level (including native students in school) of the variables mother and father education, the highest

\footnotetext{
${ }^{7}$ Moreover, reading literacy was the central focus of the PISA 2009 survey with most testing time allocated. In each wave, the central focus of PISA changes. It was science literacy in 2006 and math literacy in 2003.
} 
occupation status, and number of books at home. ${ }^{8}$ One observation with missing information on gender has been dropped. If the language spoken at home is missing, I coded it as being different than the national testing language. As discussed above, I dropped the children of immigrants whose parents both originated from Western Europe, Aussiedler-countries or Albania. ${ }^{9}$ Children with a mixed foreign background - with both parents born in a foreign country but from different areas - are included in the another origin category. Since the children of immigrants form a selective subpopulation of the overall student population in both countries, sampling weights are not likely to recover the target population of interest. The sampling design is the same in both countries, hence selection is unlikely to be correlated with the country indicator. For that reason, I refrain from using sampling and replication weights in the main analysis. $^{10}$

This selection generates a sample size of 1,180 second-generation immigrant students: 824 in Switzerland and 356 in Germany. ${ }^{11}$ In Table 2, the descriptive statistics of the background characteristics are presented.

[Table 2 about here.]

In the top row, the average reading literacy test scores exhibit already a substantial difference between the countries. The reading literacy is a standardized test measuring reading comprehension. PISA provides five plausible values, of which I take the average. ${ }^{12}$ Overall, the characteristics seem to be relatively similar in both countries.

\footnotetext{
${ }^{8}$ In Appendix C, Table C.1 and C.2 show that the missing values are positively correlated with each other and negatively with the test scores and that dropping these will change the outcome considerably. The total number of observations with at least one imputed value is 473 . The number of imputations/missings due to the covariates can be found in Table C.3. In order to show that my results are not driven by the imputation mechanism, I present in Appendix B Table B.7 a median imputations based on country level and in B.8 a regression based imputation that takes into account the covariance structure of the imputed covariates. The results are very similar. For the school characteristics presented in Table 1, I first impute the values only on immigrant students in school (to account for example for extra German lessons), and if these are not sufficient I impute them including natives.

${ }^{9}$ There is more information about the sample selection in Appendix C Table C.4. The results including these groups of immigrants' children can be found in Appendix B Table B.2.

${ }^{10}$ The main specification using sampling weights is presented in Appendix B Table B.3. Using replication weights instead of bootstrapping seems to result in smaller standard errors (results not reported).

${ }^{11}$ Hereafter, the Swiss second-generation immigrant population always refers to those in the German-speaking part. As a sensitivity check, I estimate the decompositions including the French- and the Italian-speaking parts which exhibit a similar pattern (cf. Appendix B, Table B.1). The Swiss sample includes the PISA extension survey for cantonal representativeness and has therefore a larger number of observations.

${ }^{12}$ In Appendix B Table B.6, I present the main results using only one plausible value as recommended by the PISA manual, results are almost indistinguishable.
} 
There are some differences in the educational levels of the parent generation as measured by the International Standard Classification of Education (ISCED), which is assessed by four dummy variables the first capturing no formal education, the second primary up to lower secondary, the third measures upper secondary/non-tertiary, and the fourth theoretically oriented tertiary education. In Switzerland there is a smaller share of uneducated parents and a larger share of parents who have only completed primary or lower secondary education. Conversely, in Germany a larger share of the parent generation obtained an upper secondary degree, and the proportion completed a tertiary education is smaller than in Switzerland.

On the other hand, the highest occupational status measured by the Highest Socio-Economic Index of Occupational Status (HISEI) - that ranks occupations by the returns to education and takes the highest one among the parents - is almost identical in both countries. ${ }^{13}$ There is a considerably larger number of immigrant families that speak a language other than German at home in Switzerland (81\%) than in Germany (67\%). In conventional immigrant-native comparisons these students are necessarily out-of-support. Finally, as discussed above, in the Swiss sample more children of Southern European immigrants (mainly Italians), less Turkish, and more former Yugoslavians are represented. As previous studies indicated, there is correlation in the test score performance of immigrants' children and their descent (e.g., Dustmann, Frattini and Lanzara, 2012; Dronkers and Heus, 2010; Song, 2011). Despite of the disparity between the proportions, the overlap of types of immigrants in Switzerland and Germany is much greater compared to other country pairs that have been contrasted in the literature. This enables me to control for the country of origin in greater detail than previous studies.

\subsection{Estimation strategy}

The goal of this paper is to compare the average reading test scores of immigrants' children in Switzerland $\bar{Y}_{C H E}$ and Germany $\bar{Y}_{D E U}$

$$
\Delta=\bar{Y}_{C H E}-\bar{Y}_{D E U}
$$

and to decompose this average test score gap $\Delta$, into a part that can be associated with the covariates described above and the remaining part that is not attributable to these background

\footnotetext{
${ }^{13}$ For more information on this index, see Ganzeboom, De Graaf and Treiman (1992).
} 
characteristics. The latter can capture, for example, greater integration into the host society, or more inclusive school institutions. ${ }^{14}$ These two effects are decomposed by simulating the mean and the distribution of individual and family backgrounds of the students in Switzerland (Germany) within the distribution of students' background characteristics in Germany (Switzerland). In other words, reweighing the student population in the one country to reproduce the covariate-distribution of the other.

In the parametric $\mathrm{BO}$ decomposition, the covariate-adjusted mean is estimated by performing separate linear regressions of test scores on characteristics for both groups and combining the estimated coefficients of one regression with the covariate vector of the other regression (Blinder, 1973; Oaxaca, 1973). Adding and subtracting this estimated covariate-adjusted mean, Equation (1) can be written as

$$
\Delta=\underbrace{\hat{\beta}_{C H E}\left(\bar{X}_{C H E}-\bar{X}_{D E U}\right)}_{\Delta_{X}}+\underbrace{\left(\hat{\beta}_{C H E}-\hat{\beta}_{D E U}\right) \bar{X}_{D E U}}_{\Delta_{S}}
$$

or equivalently in the reverse decomposition

$$
\Delta=\underbrace{\left(\hat{\beta}_{C H E}-\hat{\beta}_{D E U}\right) \bar{X}_{C H E}}_{\Delta_{S}}+\underbrace{\hat{\beta}_{D E U}\left(\bar{X}_{C H E}-\bar{X}_{D E U}\right)}_{\Delta_{X}},
$$

where $\Delta_{X}$ refers to the difference due to characteristics, and the main interest lies in $\Delta_{S}$ which presents the difference not explained by characteristics, called the structure effect. ${ }^{15}$ The covariate vector $X$ includes different sets of explanatory variables: I use Other covariates as a baseline specification which includes gender, age in months, educational level of parents (four dummies each), highest occupation of the parents, and number of books at home (six dummies). Additionally, I control for German spoken at home (one dummy variable) and the country of origin (four dummies), separately and jointly.

Matching generalizes the $\mathrm{BO}$ decomposition such that it does not rely on assumptions regarding functional form or out-of-support validity (Ñopo, 2008). It accounts for the possibility that the background characteristics have non-linear impacts, and that conditioning on several covariates might create subcategories that have no equivalent in the other country. Moreover,

\footnotetext{
${ }^{14}$ A similar cross-country decomposition strategy was taken by Ammermüller (2007). He decomposes the PISA test score gap between Germany and Finland, although, not specific to immigrants' children.

${ }^{15}$ For a comprehensive treatment of decomposition methods see Fortin, Lemieux and Firpo (2011).
} 
matching decomposition can be performed on the propensity score without imposing additional assumptions (Frölich, 2007).

The matching estimator replacing, for example, $\hat{\beta}_{C H E} \bar{X}_{D E U}$ is the kernel-weighted average over the test score distribution of second-generation immigrants in Switzerland:

$$
\frac{1}{N_{D E U}} \sum_{i \in I_{D E U}} \sum_{j \in I_{C H E}} w(i, j) Y_{j, C H E}
$$

where $w(i, j)$ are the kernel weights that weigh observations according to the similarity of their propensity scores (background characteristics) to those of the other countries' students. $N_{D E U}\left(N_{C H E}\right)$ is the number of immigrants' children in Germany (Switzerland), and $I_{D E U}$ $\left(I_{C H E}\right)$ is the set of immigrants' children in the common support of the other country. Analogous to the parametric procedure, the covariate-adjusted mean is added and subtracted from Equation (1) to write it as a sum of the components $\Delta_{X}$ and $\Delta_{S}$ (see Frölich, 2007, for a more comprehensive treatment).

Propensity scores are estimated by logit regressions of a country dummy on the same characteristics as in the parametric decomposition. The supports overlap greatly and imposing the common support therefore discards only very few observations. ${ }^{16}$ The kernel weights are constructed by a Nadaraya-Watson kernel regression with Gaussian kernel and bandwidth held constant at 0.1 across specifications. ${ }^{17}$ The quantile gaps are calculated by the horizontal differences between estimated quantiles of the actual and the covariate-adjusted test score distributions, constructed by the matching specification. Standard errors are bootstrapped in all decompositions with 500 replications, and the propensity scores are re-estimated in each replication.

\subsection{Interpretation}

In principle, any unexplained gap between Germany and Switzerland can be due to differences between the countries (e.g. school institutions) or due to unobserved differences in the composition of the first-generation immigrant populations. Under the assumption that there is no selection bias conditional on the included background characteristics, the gap represents the

\footnotetext{
${ }^{16}$ In Appendix C Figure C.1 I present the distribution of propensity scores over the common support.

${ }^{17}$ I present the main results using Nearest Neighbor matching with 1 and 5 neighbors and bandwidths 0.95 and 0.105 in Appendix B: Table B.4 and B.5. The effects are similar to those in my preferred specification.
} 
genuine country effect. In consequence, the observed test score performance of the matched immigrants' children in one country identifies the counterfactual outcome, i.e. the performance of the immigrants' children had their parents migrated to the respective other country. In the following, I discuss possible threats to the validity of this assumption. The assumption would be violated, if unobserved variables differ between the countries and correlate with children's test score performance.

Despite of the similar migration histories and recruitment efforts, differential self-selection of migrants between Switzerland and Germany might violate the assumption. For example, it could be the case that more motivated individuals decided to emigrate to Switzerland (which might not be accounted for by the included covariates). If their motivation is transmitted to their children and subsequently translated into higher test scores, then the unexplained part in the decomposition would comprise this selection bias. Indeed, the parental education appears to be slightly more favorably distributed among immigrants in Switzerland (cf. Table 2). This could imply a positive bias in the unexplained part in favor of Switzerland. Yet, the number of books at home - a control variable intended to capture parents' esteem in education and academic success (Schütz, Ursprung and Wößmann, 2008) - and the parents' occupations are almost indistinguishable between the two countries. Moreover, there are reasons to belief that the scope for such a selection bias is limited. First, the guest-worker scheme allowed migrant workers to temporarily leave their home countries to work and accumulate savings before they returned to their home countries. Schmid (1983) argues that this was in line with the intentions of the migrant workers. Yet, they were unable to accumulate sufficient savings and found themselves trapped in their host countries where they became permanent migrants (see also Castles, 1986). This unplanned migration pattern probably prevented sophisticated migration decisions. Second, it seems unlikely that they gathered sufficient information that enabled them to differentiate in detail between the two countries, given how similar the countries must have seemed to an outsider. Third, the migration costs must have been very similar to migrants from the same area, because Germany and Switzerland shared a common language, geographic location and prospering economic condition.

In addition, the parents might differ by the country they received their education in, which cannot be ruled out due to missing pre-migration information. For instance, it could be the 
case that the parents that migrated to Germany had acquired some of their education in Germany while those who migrated to Switzerland migrated after they finished their education in their home countries. However, I expect that most of these differences are controlled for by conditioning on the parents' level of education, occupation, and especially whether they speak German at home. All of these factors should correlate strongly with the country where an individual received its education in. Furthermore, as discussed in detail above the similar migration patterns suggest similar life-cycle stages of the migrants, i.e. guest-workers must have finished their education before migrating.

Another potential confounder is the return migration. Even when both sending populations would have been identical, if the migrants that returned to their home countries differed between the countries then the disparity will entail a selection bias due to return migration. Nevertheless, as discussed above, the return migration was minor in both countries; conversely to the attempts of the respective governments (see, inter alia, Castles, 1986; Liebig, 2004).

Finally, it could be the case that the differences in test scores stem from the differences in the ethnic composition of the immigrant populations (rather than from composition of the country of origin which is controlled for in the analysis). However, so far little is known about how the educational performance differs by ethnicity (of the second-generation) or if the composition of ethnicities differs between the two countries in a significant manner. It seems very promising to assess potential differences resulting from differences in ethnicity. Unfortunately, large scale and internationally comparable student assessments do not contain information on ethnicity which prevents a detailed analysis of ethnicity.

In sum, I focus the comparison on immigrant populations which migrated from similar areas to similar countries that share the "same" language and migration history. Moreover, I balance out differences by controlling for important background characteristics such as the parents' education level, their occupation, the language they speak at home, and their origin. Still, it is inherently possible that there is some selection based on unobservables. However, the analogies between the Swiss and the German migration experiences are rarely observed across other country pairs and time periods. Keeping these concerns in mind, it is interesting to answer how much of the test score disparity, observed in Table 2, can be explained by the covariates described above. Moreover, comparing the performance of those immigrants' children can shed 
light on the learning process of immigrants' children and what the parental migration decision implied for their children.

\section{Results}

In this section, I provide answers to the question "How would the children of immigrants perform in Switzerland (Germany) if they had the same distribution of background characteristics as those in Germany (Switzerland)?" I start by replicating the commonly used within-country second-generation immigrant-native test score regressions, in order to provide a reference for my main results.

[Table 3 about here.]

Table 3 presents separate regressions of reading test scores on an immigrant indicator and the covariate vectors explained in Section 3.2 for Germany and Switzerland. The results are comparable to those in Dustmann, Frattini and Lanzara (2012, Table 4) for the survey of 2006. In Column 1 Panel A, the unconditional reading test score gap between second-generation immigrant and native students is -58.32 test score points in Germany and -48.72 in Switzerland (Panel B). Including individual and family characteristics reduces the gap significantly, as presented in Column 2. Furthermore, the gap narrows substantially by adding the German spoken at home indicator, leaving only -7.91 points remaining unexplained in Germany and -6.62 in Switzerland (Column 3). In Columns 4 to 6, I present the same procedure for the subsample of immigrants exposed to a German-speaking environment and with the exclusion of Aussiedler, Albanians, and Western European immigrants' children. The regression coefficients are larger in Germany, implying that Aussiedler have driven the gap downwards. In Switzerland, the selected subsample seems to perform slightly worse than the overall sample. As discussed in detail earlier, it is impossible to draw conclusions regarding which country better supports the educational achievement of second-generation immigrants from these results alone.

Turning to my main analysis, Figure 1 depicts the unconditional reading test score densities of immigrants' children in Germany and in German-speaking Switzerland (left panel).

[Figure 1 about here.] 
The left graph shows that reading test scores tend to be higher in Switzerland. The right graph depicts the unconditional quantile gap, which is the horizontal difference between the countries' distribution functions at various quantiles. The quantile gap is positive almost everywhere and is particularly large and statistically significant among low-performing students. This indicates, that the low-performing second-generation immigrants score substantially higher in German-speaking Switzerland than in Germany. In the following, I present evidence that this relationship holds when conditioning on background characteristics.

\subsection{Mean difference}

I start by decomposing the average reading test score difference, shown in Table 4. In Panel A, I adjust the second-generation immigrant population in Switzerland to match the characteristics of the second-generation immigrants in Germany. In Panel B, I reversely adjust the children of immigrants' characteristics in Germany to match those in Switzerland.

Column 1 presents the unconditional average reading test scores of immigrants' children in Switzerland (457.09) and Germany (439.05). The unconditional mean difference $\Delta_{S}$ is 18.05, which is both significantly different from zero and large in magnitude (and of course equivalent in Panel A/B). As a reference, this is roughly $30 \%$ of what an additional school year adds in my subsample of immigrants' children. ${ }^{18}$

Columns 2-5 present the parametric BO decomposition and Columns 6-9 the semi-parametric matching decomposition. Column 2 (and 6) uses the vector of Other background characteristics as above, 3 (and 7) adds the German spoken at home indicator, 4 (and 8) controls instead for the country of origin, and the last specification in Column 5 (and 9) uses in addition both language and origin indicators.

[Table 4 about here.]

Starting with Panel A Column 2, the covariate-adjusted mean among Swiss students with German students' characteristics is 453.03. Although their performance decreases, it remains 13.99 points higher than what was actually observed in Germany. This difference is large in magnitude and statistically significant. Controlling for the language spoken at home widens

\footnotetext{
${ }^{18}$ Ammermüller $(2007,271)$ finds that "[a]n additional year of schooling adds [...] 38 points in Germany" for the overall student population.
} 
the gap, leaving 17.05 points unexplained. By contrast, when the adjustment is performed including the country of origin, instead of the language indicator, the test score disparity narrows. Including both jointly, it amounts to 9.50 which is not statistically significant but relevant in magnitude.

Compared to the matching decompositions in Columns 6 to 9, the results are confirmed with higher point estimates for the unexplained part. Here, when conditioning on country of origin in Column 8, the differences are larger than in the BO decomposition. The gap amounts to 13.39 test score points when including both language and origin (Column 9). Differences to the $\mathrm{BO}$ decompositions might be explained by violations of linearity or validity out-of-support, since the BO decomposition procedure simply predicts values for empty covariate-cells.

Panel B presents the results for the reverse adjustment. The structure effect now measures the difference between children of immigrants in Switzerland and immigrants' children in Germany with adjusted characteristics. Interestingly, in Column 2, the adjusted gap is larger than the unconditional gap. This is because adjusting to the characteristics of immigrants' children in Switzerland causes even lower performance for students in Germany, 430.66 on average, than those of the actual second-generation immigrant population in Germany, demonstrating a negative composition effect. The structure effect increases from 26.44 to 30.43 when adding German spoken at home as an additional control in Column 3. Recall that this is more than half a school year in the sample of immigrants and almost a full year equivalent for the overall student population. In Column 4, adding the origin of the student's parents instead decreases the gap to 23.20 and controlling for both the gap is 27.25 - statistically significant and large in magnitude. Compared to the matching results in Columns 6-9, the effects show the same increasing pattern when the adjustment is performed on individual and family characteristics, and further increases when the language indicator is included. The specifications that include country of origin exhibit a smaller disparity in performance.

In sum, I find the gap that cannot be explained by differences in covariates to be positive in all, and large in magnitude and statistically significant in most specifications. The key finding is that the students in Switzerland outperform those in Germany at the mean. Of this disparity only a small part is attributable to differences in background characteristics. Noteworthy, including the language spoken at home increases the unexplained part in all specifications. 
This suggests that Switzerland supports performance especially well for those who do not speak German at home. In the next section, I extend the analysis to the distribution of the reading test scores.

\subsection{Distribution}

The decompositions along the test score distribution are presented in Figures 2 and 3. Panel A presents the adjustments including the vector of Other background covariates and the German spoken at home, and Panel B adds the origin indicators. As in Figure 1, the left panel presents the reading test score densities and the right panel the quantile gaps. The adjusted quantile gaps are depicted by the solid lines and bootstrapped confidence intervals by the dotted lines (black for $95 \%$ and gray for $90 \%$ confidence intervals). As a reference, I add the unadjusted quantile gap (dashed line) from Figure 1.

[Figure 2 about here.]

Starting with the adjustment of Swiss students to Germans characteristics, the density of immigrants' test scores in Switzerland does not align to the one of Germany. Accordingly, the gap remains roughly unchanged, as can be observed by the adjusted quantile gap in the right panel (solid line). This shows that, conditional on background characteristics, the large performance gap among low-performing children of immigrants remains and even widens slightly for the very well performing students. Including the origin of the parents aligns the adjusted Swiss students test score density more closely with the density of second-generation immigrants in Germany. Nevertheless, the gap for the very low-performing immigrants' children remains statistically significant and of considerable magnitude. The adjusted quantile gap is positive almost everywhere, though smaller in the medium percentiles and greater in the top percentiles than without taking the origin of the parents into account. Conditioning on origin increases the noise substantially rendering the gap only marginally significant at some parts of the distribution.

[Figure 3 about here.]

The reverse adjustment is presented in Figure 3. In Panel A, the adjusted test score density among German students increases at a score of about 400 and decreases above 500 points. This 
projects an even lower performance for adjusted German students than the actual German students as discussed above. As shown in the right panel, the quantile gap increases in almost all quantiles. Including the country of origin indicators in Panel B, the density of German students adjusted to Swiss students' characteristics aligns more closely with the immigrants' children in Switzerland when the country of origin is included. Again, the very low-performing students are only found in Germany. Overall, the quantile gap appears to be positive in general, but is only marginally significantly different from zero.

Investigating the effects along the distributions of reading test scores, I find the structure effect to be largest among the very low-performing students. In all adjustments, the unexplained differences are substantial in magnitude for those that need the most support. The results confirm that performance is higher in Switzerland in all specifications and the gap remains mostly positive and marginally significant throughout the distribution when the country of origin is controlled for.

\subsection{Subgroup analysis}

"Which country supports the children of immigrants that face the most disadvantageous circumstances?" is one of the key questions for Western European policy makers, that are facing a growing number of children with migration background. "How do children descending from a specific origin compare to the results above?" and "does this disparity also exist between children of natives?" In Table 5, I address these questions by performing the decompositions separately on restricted samples of the student population, namely to: Those who have the most unfavorable background characteristics (Columns 1-3); children of Turkish immigrants, the larges overlapping immigrant population (Columns 4-6); and native students (Columns 79). Each first column presents the unconditional gap, the second the BO adjustment, and the third the matching adjustment.

[Table 5 about here.]

In Columns 1-3, I restrict attention to second-generation immigrant students whose parents have either no education or only primary to lower secondary education (ISCED 0-2) and who 
do not speak German at home. ${ }^{19}$ This procedure drastically reduces the sample to 296 observations - 57 in Germany and 212 in Switzerland - so results have to be interpreted cautiously. Unsurprisingly, the average test scores are lower in both countries (Column 1). Meanwhile, the unconditional gap increases sharply to 56.45 points, which is statistically significant and very large in magnitude. This subset of students performs better by more than a full year equivalent of schooling in Switzerland than in Germany. In Panel A Columns 2 and 3, when Swiss students are adjusted to German students' characteristics, the parametric and semi-parametric estimates of the structure effect are similar and substantial in magnitude, ranging from 30.15 to 36.78 test score points. Although parametric and matching estimates are still very large in magnitude, in the reverse decomposition (Panel B), they exhibit a greater dispersion ranging from 22.64 to 43.25 points. The gap is much larger in magnitude compared to the unconstrained sample of immigrants' children, suggesting that this subset is served much better in Switzerland than in Germany.

The parents' country of origin has been discussed as a potential explanation for some of the international variation in second-generation immigrant-native test score gaps. The children of Turkish descendants have attracted some attention since they represent a large enough population to be compared across countries (e.g., Dustmann, Frattini and Lanzara, 2012; Song, 2011). In Columns 4 to 6, I present the mean results for children of Turkish descent only, using all Other covariates and the German spoken at home indicator. Unconditionally, children of Turkish descent score 431.26 in Switzerland and 417.97 in Germany. While both scores are far below the international average of 500, they score 13.29 points higher in Switzerland than in Germany, although the difference is not statistically significant (probably due to the reduced sample size). In the Panel A decomposition, the unexplained gap amounts to 20.31 test score points, and in the reverse decomposition of Panel B to 34.22 test score points, which is statistically significant. The unexplained gap is large and consistently positive throughout the decompositions. The students - whose parents migrated from Turkey and who are subsequently born and raised within a German-speaking environment - in Switzerland substantially outperform those in Germany, especially after adjusting for background characteristics.

\footnotetext{
${ }^{19}$ Applying these restrictions effectively constrains the books at home, since there are no observations with more than 200 books at home in Germany and only two in Switzerland.
} 
The economics of education literature has predominantly focused on educational integration, hence it is natural to ask what the adjustment mechanism returns when applied to natives' children. In Columns 7 to 9, I present the mean achievement gap for native students. First, it is important to note that the parental education category of no primary education is empty in Germany and nearly empty in Switzerland and consequently excluded from the specification. In Column 7, the average performance of Swiss children is better than that of German children, which would even increase some difference-in-differences measure of integration. Conditionally, this gap is reversed in both adjustments, meaning that the Swiss (German) students with German (Swiss) characteristics perform better (worse) than the observed Swiss (German) students, but only by a relatively small amount. Hence, natives' children also perform better in Switzerland, but notably less than their counterparts with a migration background.

\subsection{Discussion}

It is difficult to single out which institutional factors cause the large performance disparity, since educational institutions differ not only between but also within countries. I therefore end with a suggestive discussion of some features that might explain the large unexplained test score differences documented above. The decomposition results including school characteristics are presented in Table 6 (the descriptive statistics of the variables are presented in Table 1 above). Columns 3 and 7 of Table 4 are presented again in Columns 1 and 5 to serve as a benchmark.

[Table 6 about here.]

Since the unexplained performance gap always increases when conditioning on language spoken at home, the Swiss system seems to be more capable in teaching its immigrants' children German reading literacy, especially to those who do not speak German at home. One possible explanation could be that - since all Swiss students do speak some dialect at home - the Swiss educational system has developed institutions that enhance second-language acquisition better than those in Germany. One way to assess whether there is a greater emphasis on learning German in the Swiss curriculum is to compare the amount of German language-lessons per week. On average, immigrant students in Switzerland report to visit more German classes as well as overall lessons per week than those in Germany (cf. Table 1). In Columns 2 and 7, I perform the decomposition using the Other background characteristics, the German spoken at home, 
the amount of German lessons, and the overall amount of lessons in school. It is important to note that there are a few missing values at the school level, hence the decompositions are based on a slightly reduced sample with average test scores of 456.22 in Switzerland and 442.49 in Germany. The unconditional gap amounts to 13.74 and essentially remains unaffected by the inclusion of the amount of lessons in all four decompositions. Notwithstanding, the amount of teaching is distinct from its quality which still might greatly influence the students' achievement. Interestingly, as shown in Table 1 above, the children in Germany visit twice as many out-ofschool-time lessons in German. ${ }^{20}$ It remains an open question whether the reading test score gap would even have been larger without the additional instruction time.

Early ability tracking is an intensively debated institution in both countries. The Swiss system tracks students between one and two years later in their school careers than the German system. This might cause the low performing students in Germany to fall behind their Swiss counterparts. On a distinct but related note, a result of early tracking could be segregation and placement of disadvantaged students in schools and/or classes. Similarly, Cattaneo and Wolter (2012) discuss that changes in the school composition - due to the increased number of children that speak German at home - can positively impact PISA performance of immigrant students with a migration background. Accordingly, if immigrant students are segregated they might have little reason or opportunity to learn German. Hence, the test score disparity may reflect the disparity in school compositions.

To address potential segregation, I calculate the proportions of second-generation immigrant students in school and define a categorical variable measured in $10 \%$ steps. On average in Germany, immigrants' children have $40 \%$ immigrants as peers in school, whereas the share is $34 \%$ in Switzerland (one should keep in mind that the overall share of immigrants is larger in Switzerland than in Germany). In Columns 3 and 8, when adjusting for the proportion of immigrants' children in school the unexplained gap reduces in all decompositions by a relatively small amount.

Another way to address the segregation is to control for the performance of the students' peers. Despite being highly endogenous, as explained by Manski (1993), it is still interesting

\footnotetext{
${ }^{20}$ The out-of-school-time lessons were assessed by the question: How many hours do you typically spend per week attending out-of-school-time lessons in German (at school, at home or somewhere else)? The answer categories were: 0, 0-2, 2-4, 4-6, 6 hours. To compare the averages, I take midpoint of the categories, 0 for the lowest, and 6 for the highest category.
} 
to assess if peer performance can account for some of the unexplained test score gap. First, I calculate the average performance of second-generation immigrant students in school. In a second step, I additionally include native students. ${ }^{21}$ The average reading test scores of the immigrant peers (and additional natives) is 470.27 (496.42) in Switzerland and 456.81 (476.54) in Germany. Including the performance of immigrants' children in the decomposition (Columns 4 and 9), the unexplained part of the gap reduces substantially. In addition, including the performance of natives' children (Columns 5 and 10), the disparity almost drops to 0, being insignificant in all specifications.

I do not want to over-emphasize these results due to the obvious endogeneity and the non-causal nature of the decomposition estimates. Yet, keeping in mind that the measure is problematic, the results point to a greater segregation and clustering of low-performing students in Germany. It seems promising to explore if the better performance is caused on the school level in greater detail. Furthermore, the finding highlights that if we seek to understand the secondgeneration immigrant students' achievement process, we have to find suitable comparison groups and a promising candidate being second-generation immigrant students in similar environments.

In sum, it appears that immigrants' children in German-speaking Switzerland exhibit greater reading (and math, cf. Appendix A) literacy than their counterparts in Germany. This difference prevails or even increases when adjusting for their personal, socio-economic, and educational characteristics. While the results are strong and unequivocal, their interpretation require caution, one must bear in mind that there might be other potential factors causing these differences in test scores which are not part of educational institutions, such as attitudes towards immigrants or integration efforts in general. In addition, it is of course possible that there is still some selection on unobservables. However, by decomposing the educational achievement gap conditionally on important background characteristics and using only those students that migrated from similar areas to similar countries that share the "same" language and migration history, it seems implausible that selection on unobservables alone causes these large differences in educational performance. Moreover, as the gap vanishes almost entirely by the inclusion of school system characteristics raises confidence in an explanation based on the educational systems.

\footnotetext{
${ }^{21}$ I use a categorical variable based on 25 test score point steps between 300 to 650 . For the average peer test scores and the proportion of immigrants in school, results are robust to variations in the binning steps (results available upon request).
} 


\section{Conclusion}

In this study I have proposed a new approach to investigate second-generation immigrants' learning processes by contrasting their performance across countries. Applying this reasoning, I have compared the immigrants' children in Germany with those in the German-speaking part of Switzerland to assure the students' comparability. Based on PISA 2009 survey results, I adjusted the test score distributions in Germany and German-speaking Switzerland for the composition of the second-generation immigrant population in the respective other country.

My results establish that the second-generation immigrants' reading literacy is substantially greater in Switzerland. This difference is large in magnitude, especially for low-performing students. The most crucial difference seems to be the language spoken at home. When it is different from German, it always increases the gap that cannot be explained by the students' background characteristics. These differences are robust to the inclusion of the parents' country of origin. Additionally, Switzerland seems to be particularly beneficial for unfavorably-endowed children of immigrants and the children of Turkish immigrants while being relatively less beneficial for children of native-born parents. 


\section{References}

Algan, Y., C. Dustmann, A. Glitz and A. Manning. 2010. "The Economic Situation of First and Second-Generation Immigrants in France, Germany and the United Kingdom." The Economic Journal 120(542):F4-F30.

Ammermüller, A. 2007. "PISA: What makes the difference? Explaining the gap in test scores between Finland and Germany." Empirical Economics 33(2):263-287.

Ammermüller, A., H. Heijke and L. Wößmann. 2005. "Schooling quality in Eastern Europe: Educational production during transition." Economics of Education Review 24(5):579 - 599.

Belzil, C. and F. Poinas. 2010. "Education and early career outcomes of second-generation immigrants in France." Labour Economics 17(1):101 - 110.

Blinder, A. S. 1973. "Wage Discrimination: Reduced Form and Structural Estimates." Journal of Human Resources 8(4):436-455.

Castles, S. 1986. "The Guest-Worker in Western Europe - An Obituary." International Migration Review 20(4):761-778.

Cattaneo, A. and S. Wolter. 2012. "Migration Policy Can Boost PISA Results: Findings from a Natural Experiment." IZA Discussion Paper No. 6300.

Dronkers, J. and M. Heus. 2010. Negative selectivity of Europe's guest-workers immigration? The educational achievement of children of immigrants compared with the educational achievement of native children in their origin countries. In From Information to Knowledge; from Knowledge to Wisedom: Challenges and Changes facing Higher Education in the Digital Age, ed. E. de Corte and J. Fenstad. London: Portland Press pp. 89 - 104.

Dustmann, C., T. Frattini and G. Lanzara. 2012. "Educational achievement of secondgeneration immigrants: an international comparison." Economic Policy 27(69):143-185.

EDK. 2002. Schweizerische Konferenz der kantonalen Erziehungsdirektoren. Grundlegende Informationen zum Bildungswesen, Bern.

Entorf, H. and N. Minoiu. 2005. "What a Difference Immigration Policy Makes: A Comparison of PISA Scores in Europe and Traditional Countries of Immigration." German Economic Review 6(3):355-376.

Fortin, N., T. Lemieux and S. Firpo. 2011. Decomposition Methods in Economics. In Handbook of Labor Economics, ed. O. Ashenfelter and D. Card. Vol. 4, Part A Elsevier pp. 1 - 102.

Frölich, M. 2007. "Propensity score matching without conditional independence assumptionwith an application to the gender wage gap in the United Kingdom." Econometrics Journal 10(2):359-407.

Ganzeboom, H. B. G., P. M. De Graaf and D. J. Treiman. 1992. "A standard international socio-economic index of occupational status." Social Science Research 21(1):1-56.

Häberlin, U., C. Imdorf and W. Kronig. 2004. Von der Schule in die Berufslehre: Untersuchungen zur Benachteiligung von ausländischen und von weiblichen Jugendlichen bei der Lehrstellensuche. Berne: Haupt Verlag.

Hansen, R. 2003. "Migration to Europe since 1945: its history and its lessons." Political Quarterly 74(s1):25-38. 
Heath, A. F., C. Rothon and E. Kilpi. 2008. "The Second Generation in Western Europe: Education, Unemployment, and Occupational Attainment." Annual Review of Sociology 34:211235.

KB. 2006. Bildung in Deutschland. Konsortium Bildungsberichterstattung. Bertelsmann Verlag GmbH \& Co. KG, Bielefeld.

Levels, M., J. Dronkers and G. Kraaykamp. 2008. "Immigrant Children's Educational Achievement in Western Countries: Origin, Destination, and Community Effects on Mathematical Performance." American Sociological Review 73(5):835-853.

Liebig, T. 2004. Recruitment of foreign labour in Germany and Switzerland. In Migration for Employment: Bilateral Agreements at a Crossroads, ed. OECD, Integration Federal Office of Immigration and Emigration. OECD Publishing, Paris pp. 157-186.

Lüdemann, E. and G. Schwerdt. 2012. "Migration background and educational tracking." Journal of Population Economics 26(2):455-481.

Luthra, R. R. 2010. Assimilation in a New Context: Educational Attainment of the Immigrant Second Generation in Germany. ISER Working Paper No. 2010-21.

Manski, C. F. 1993. "Identification of Endogenous Social Effects: The Reflection Problem." Review of Economic Studies 60(3):531-542.

Mayda, A. M. 2006. "Who is against immigration? A cross-country investigation of individual attitudes toward immigrants." Review of Economics and Statistics 88(3):510-530.

Ñopo, H. 2008. "Matching as a Tool to Decompose Wage Gaps." Review of Economics and Statistics 90(2):290-299.

Oaxaca, R. 1973. "Male-Female Wage Differentials in Urban Labor Markets." International Economic Review 14(3):693-709.

OECD. 2009. PISA Data Analysis Manual (SPSS, second edition). Paris, OECD.

Ohinata, A. and J. C. van Ours. 2012. "Young Immigrant Children and their Educational Attainment." Economic Letters 116(3):288-290.

van Ours, J. C. and J. Veenman. 2003. "The educational attainment of second-generation immigrants in The Netherland." Journal of Population Economics 16(4):739-753.

Schmid, C. 1983. "Gastarbeiter in West Germany and Switzerland: an Assessment of Host Society-Immigrant Relations." Population Research and Policy Review 2:233-252.

Schütz, G., H. W. Ursprung and L. Wößmann. 2008. "Education Policy and Equality of Opportunity." Kyklos 61(2):279-308.

Schneeweis, N. 2011. "Educational institutions and the integration of migrants." Journal of Population Economics 24(4):1281-1308.

Schnepf, S. V. 2008. Inequality of Learning Amongst Immigrant Children in Industrialised Countries. IZA Discussion Paper No. 3337.

Segal, C. 2012. "Working When No One Is Watching: Motivation, Test Scores, and Economic Success." Management Science 58(8):1438-1457.

Song, S. 2011. "Second-generation Turkish youth in Europe: Explaining the academic disadvantage in Austria, Germany, and Switzerland." Economics of Education Review 30(5):938-949. 
Zimmermann, K. F. 1995. "Tackling the European Migration Problem." Journal of Economic Perspectives 9(2):45-62. 
Table 1: Descriptive STATISTICS OF SCHOOL CHARACTERISTICS VISITED BY SECOND-GENERATION IMMIGRANT STUDENTS BY COUNTRY

\begin{tabular}{|c|c|c|}
\hline Variables & Switzerland & Germany \\
\hline \multirow[t]{3}{*}{ Years visited preschool } & 2.79 & 2.67 \\
\hline & $(0.44)$ & $(0.61)$ \\
\hline & {$[814]$} & [341] \\
\hline \multirow{3}{*}{ Age at school entry } & 6.69 & 6.41 \\
\hline & $(0.60)$ & $(0.59)$ \\
\hline & {$[778]$} & {$[335]$} \\
\hline \multirow[t]{3}{*}{ Grade at testing } & 8.80 & 8.97 \\
\hline & $(0.57)$ & $(0.73)$ \\
\hline & {$[824]$} & {$[335]$} \\
\hline \multirow[t]{2}{*}{ Grade repetition } & 0.30 & 0.34 \\
\hline & {$[820]$} & [343] \\
\hline \multicolumn{3}{|l|}{ Number of } \\
\hline \multirow[t]{3}{*}{ German lessons in school } & 4.34 & 4.10 \\
\hline & $(1.10)$ & $(0.99)$ \\
\hline & {$[824]$} & {$[345]$} \\
\hline \multirow[t]{3}{*}{ all lessons in school } & 33.65 & 31.81 \\
\hline & $(3.44)$ & $(3.84)$ \\
\hline & {$[809]$} & {$[343]$} \\
\hline \multirow{3}{*}{ German lessons out-of-school } & 0.32 & 0.68 \\
\hline & $(1.03)$ & (1.48) \\
\hline & {$[593]$} & {$[219]$} \\
\hline \multirow{4}{*}{$\begin{array}{l}\text { Proportion of migrants in school } \\
\text { Average reading test score } \\
\quad \text { immigrants' children in school }\end{array}$} & 0.34 & 0.40 \\
\hline & & \\
\hline & 470.27 & 456.81 \\
\hline & $(65.75)$ & $(81.32)$ \\
\hline \multirow[t]{2}{*}{+ natives in school } & 496.42 & 476.54 \\
\hline & $(57.63)$ & $(77.10)$ \\
\hline
\end{tabular}

Note: Switzerland refers to the German-speaking part only. School level variables imputed on school level first on immigrants' children responses and if still missing on those of natives as well. Standard deviations are given in round and number of observations if they differ from those in the main specification (CHE: 824; DEU: 356) in squared brackets. Grade repetition is an indicator variable that is one when the student repeated one or more grades and can be interpreted as percentage points. German lessons out-of-school was assessed categorically, the average is taken after redefinition by the midpoint of the categories that represent hours (the highest category was 6 and more, which is coded as 6). Proportion of second-generation migrants in school is calculated by the ratio of immigrants' children to immigrants' and native' children in school, and then binned into 10 percentage point steps. The average reading test scores are first calculated by using only the second-generation migrants in school and then additionally using the natives in school. These are then also binned into categories of 25 test score point steps from 300 to 650 .

Source: PISA 2009, own calculations. 
Table 2: Descriptive StATISTICS OF SECOND-GENERATION IMMIGRANT STUDENTS By COUNTRY

\begin{tabular}{|c|c|c|}
\hline Variables & Switzerland & Germany \\
\hline \multirow[t]{2}{*}{ Reading literacy score } & 457.09 & 439.05 \\
\hline & $(87.52)$ & $(95.95)$ \\
\hline \multirow[t]{2}{*}{ Age (in months) } & 189.83 & 189.71 \\
\hline & $(3.39)$ & (3.48) \\
\hline Male & 0.51 & 0.52 \\
\hline \multicolumn{3}{|l|}{ Education mother (ISCED) } \\
\hline No education (0) & 0.06 & 0.20 \\
\hline Primary (1,2) & 0.42 & 0.21 \\
\hline Secondary $(3,4)$ & 0.29 & 0.42 \\
\hline Tertiary $(5,6)$ & 0.23 & 0.17 \\
\hline \multicolumn{3}{|l|}{ Education father (ISCED) } \\
\hline No education (0) & 0.03 & 0.16 \\
\hline Primary (1,2) & 0.36 & 0.17 \\
\hline Secondary $(3,4)$ & 0.30 & 0.41 \\
\hline Tertiary $(5,6)$ & 0.31 & 0.26 \\
\hline \multirow[t]{2}{*}{ Highest occupation (HISEI) } & 41.61 & 40.51 \\
\hline & $(14.18)$ & $(13.93)$ \\
\hline \multicolumn{3}{|l|}{ Books at home } \\
\hline $0-10$ & 0.29 & 0.31 \\
\hline $11-25$ & 0.26 & 0.21 \\
\hline $26-100$ & 0.29 & 0.28 \\
\hline $101-200$ & 0.09 & 0.12 \\
\hline $201-500$ & 0.05 & 0.05 \\
\hline More than 500 & 0.02 & 0.03 \\
\hline German spoken at home & 0.19 & 0.33 \\
\hline \multicolumn{3}{|l|}{ Country of origin } \\
\hline Southern Europe & 0.14 & 0.06 \\
\hline Yugoslavia & 0.48 & 0.07 \\
\hline Turkey & 0.13 & 0.53 \\
\hline Another origin & 0.16 & 0.29 \\
\hline Observations & 824 & 356 \\
\hline
\end{tabular}

Note: Switzerland refers to the German-speaking part only. All numbers are relative frequencies except for reading literacy, age in months, and hisei, for which standard deviations are given in round brackets. Reading literacy is the average of five plausible values provided by PISA. The parental education is summarized by four indicators according to the International Standard Classification of Education (ISCED), where No education (0) indicates that the parent has no formal education; Primary $(1,2)$ captures primary and lower secondary education; Secondary $(3,4)$ indicates upper secondary education and post-secondary (no tertiary education); and Tertiary $(5,6)$ indicates any tertiary education. The highest occupational status of the parents (HISEI) as provided by PISA, measures highest occupational status of the parents where higher values correspond to occupations with high returns to education. Southern Europe includes Greece, Italy, Portugal, and Spain; Yugoslavia: Bosnia and Herzegovina, Croatia, FYR Montenegro and Serbia; Another country was a category in the PISA Questionnaire and includes parents originating from different areas.

Source: PISA 2009, own calculations. 
Table 3: SECOND-GENERATION IMmigrant-NATIVE STUDENTS READING TEST SCORE GAPS

\begin{tabular}{|c|c|c|c|c|c|c|}
\hline & \multicolumn{3}{|c|}{ Overall sample } & \multicolumn{3}{|c|}{ Selected sample } \\
\hline & (1) & (2) & (3) & (4) & (5) & (6) \\
\hline \multicolumn{7}{|c|}{ Panel A: Germany } \\
\hline & & & & \multicolumn{3}{|c|}{ without Aussiedler } \\
\hline \multirow[t]{2}{*}{ Immigrant } & -58.32 & -21.65 & -7.91 & -73.66 & -32.31 & -18.99 \\
\hline & $(4.39)$ & $(4.07)$ & $(4.49)$ & $(5.30)$ & $(5.29)$ & $(6.13)$ \\
\hline Observations & 3,791 & 3,791 & 3,791 & 3,632 & 3,632 & 3,632 \\
\hline \multicolumn{7}{|c|}{ Panel B: Switzerland } \\
\hline & & & & \multicolumn{3}{|c|}{ German-speaking } \\
\hline \multirow{2}{*}{ Immigrant } & -48.72 & -17.86 & $\begin{array}{c}-6.62 \\
-1\end{array}$ & -54.06 & -21.86 & 0.24 \\
\hline & $(2.33)$ & $(2.32)$ & $(2.71)$ & $(3.27)$ & $(3.24)$ & $(4.39)$ \\
\hline \multirow[t]{2}{*}{ Observations } & 8,292 & 8,292 & 8,292 & 5,249 & 5,249 & 5,249 \\
\hline & & & & \multicolumn{3}{|c|}{$\begin{array}{l}\text { German-speaking without } \\
\text { Western Europeans } \\
\text { and Albanians }\end{array}$} \\
\hline Immigrant & & & & $\begin{array}{r}-55.47 \\
(3.30)\end{array}$ & $\begin{array}{c}-21.72 \\
(3.35)\end{array}$ & $\begin{array}{l}-0.18 \\
(4.70)\end{array}$ \\
\hline Observations & & & & 5,189 & 5,189 & 5,189 \\
\hline \multicolumn{7}{|l|}{ Covariates } \\
\hline Other & No & Yes & Yes & No & Yes & Yes \\
\hline Language & No & No & Yes & No & No & Yes \\
\hline
\end{tabular}

Note: Immigrants' children are born within the country of testing and have both parents born outside of the country. Natives' children have both parents born in the country of testing. (1) and (4) report OLS regressions of reading test scores on an Immigrant indicator variable; (2) and (5) additionally include individual and family background characteristics (Other); (3) and (6) add the German speaking at home indicator, each for the respective sample selection. Robust standard errors are given in brackets.

Source: PISA 2009, own calculations. 
Table 4: Mean gap decomposition Between Swiss and German immigrants' Children Reading TEST SCORES, ADJUSTED TO OTHER COUNTRIES CHARACTERISTICS

\begin{tabular}{|c|c|c|c|c|c|c|c|c|c|}
\hline & Actual & \multicolumn{4}{|c|}{$\mathrm{BO}$ adjustment } & \multicolumn{4}{|c|}{ Matching adjustment } \\
\hline & $(1)$ & $(2)$ & $(3)$ & $(4)$ & $(5)$ & $(6)$ & $(7)$ & $(8)$ & $(9)$ \\
\hline \multicolumn{10}{|c|}{ Panel A: Swiss students adjusted to German students' characteristics } \\
\hline$Y_{C H E}$ & 457.09 & 453.03 & 456.09 & 445.78 & 448.54 & 455.56 & 458.22 & 451.26 & 452.44 \\
\hline \multirow{3}{*}{$\begin{array}{l}Y_{D E U} \\
\Delta_{X}\end{array}$} & 439.05 & & & & & & & & \\
\hline & & 4.06 & 1.00 & 11.31 & 8.55 & 1.53 & -1.13 & 5.84 & 4.65 \\
\hline & & $(3.60)$ & $(3.93)$ & $(5.44)$ & $(5.59$ & $(3.08)$ & $(3.15)$ & $(5.82)$ & $(5.49)$ \\
\hline \multirow[t]{2}{*}{$\Delta_{S}$} & 18.05 & 13.99 & 17.05 & 6.74 & 9.50 & 16.52 & 19.18 & 12.21 & 13.39 \\
\hline & $(5.78)$ & $(6.05)$ & $(5.74)$ & $(6.79)$ & $(7.13)$ & $(5.71)$ & (5.76) & $(7.24)$ & $(7.09)$ \\
\hline
\end{tabular}

Panel B: German students adjusted to Swiss students' characteristics

$Y_{C H E} \quad 457.09$

\begin{tabular}{cccccccccc}
$Y_{D E U}$ & 439.05 & 430.66 & 426.67 & 433.90 & 429.85 & 438.00 & 433.84 & 444.75 & 443.97 \\
\cline { 2 - 10 }$\Delta_{X}$ & & -8.39 & -12.38 & -5.15 & -9.20 & -1.04 & -5.21 & 5.70 & 4.92 \\
& & $(4.75)$ & $(5.47)$ & $(9.09)$ & $(9.62)$ & $(3.76)$ & $(4.27)$ & $(6.98)$ & $(7.03)$ \\
$\Delta_{S}$ & 18.05 & 26.44 & 30.43 & 23.20 & 27.25 & 19.09 & 23.25 & 12.34 & 13.13 \\
& $(5.78)$ & $(6.41)$ & $(6.72)$ & $(9.65)$ & $(9.99)$ & $(6.03)$ & $(6.24)$ & $(8.36)$ & $(8.03)$
\end{tabular}

$\begin{array}{clllllllll}\text { Covariates } & & & & & & & \\ \text { Other } & \text { No } & \text { Yes } & \text { Yes } & \text { Yes } & \text { Yes } & \text { Yes } & \text { Yes } & \text { Yes } & \text { Yes } \\ \text { German } & \text { No } & \text { No } & \text { Yes } & \text { No } & \text { Yes } & \text { No } & \text { Yes } & \text { No } & \text { Yes } \\ \text { Origin } & \text { No } & \text { No } & \text { No } & \text { Yes } & \text { Yes } & \text { No } & \text { No } & \text { Yes } & \text { Yes }\end{array}$

Observations

$\begin{array}{rccccccccc}N & 1,180 & 1,180 & 1,180 & 1,180 & 1,180 & 1,152 & 1,153 & 1,023 & 1,037 \\ N_{C H E} & 824 & 824 & 824 & 824 & 824 & 797 & 798 & 668 & 682 \\ N_{D E U} & 356 & 356 & 356 & 356 & 356 & 355 & 355 & 355 & 355\end{array}$

Note: Immigrants' children are born within the country of testing and have both parents born outside of the country. (1) Unconditional gap; (2) to (5) BO adjustment: uses a twofold Blinder-Oaxaca decomposition based on (2) gender, age in month, educational level of parents, highest occupation of the parents and number of books at home; (3) adds German spoken at home; (4) uses (2) and country of origin, and (5) uses (2), (3), and (4); (6) to (9) Matching adjustment is performed by propensity score matching with Gaussian kernel and bandwidth 0.1 , the propensity scores are estimated by logit regressions on the same covariates as the in BO adjustment. All standard errors given in brackets, are simulated with 500 bootstrap replications.

Source: PISA 2009, own calculations. 
Table 5: Mean gap decomposition Between Swiss and German Children Reading test SCOREs, ADJUSTED TO OTHER COUNTRIES CHARACTERISTICS

\begin{tabular}{|c|c|c|c|c|c|c|c|c|c|}
\hline & \multicolumn{3}{|c|}{ Unfavorable background } & \multicolumn{3}{|c|}{ Turkish } & \multicolumn{3}{|c|}{ Natives } \\
\hline & $(1)$ & $(2)$ & $(3)$ & $(4)$ & $(5)$ & $(6)$ & $(7)$ & $(8)$ & $(9)$ \\
\hline \multicolumn{10}{|c|}{ Panel A: Swiss students adjusted to German students' characteristics } \\
\hline$Y_{C H E}$ & 441.08 & 414.77 & 421.41 & 431.26 & 439.23 & 438.28 & 512.62 & 518.30 & 514.51 \\
\hline \multirow{3}{*}{$\begin{array}{r}Y_{D E U} \\
\Delta_{X}\end{array}$} & 384.63 & & & 417.97 & & & 513.52 & & \\
\hline & & 26.31 & 19.67 & & -7.97 & -7.03 & & -5.68 & -1.89 \\
\hline & & $(9.12)$ & $(9.65)$ & & $(11.28)$ & $(9.69)$ & & $(1.08)$ & $(0.66)$ \\
\hline \multirow[t]{2}{*}{$\Delta_{S}$} & 56.45 & 30.15 & 36.78 & 13.29 & 21.26 & 20.31 & -0.90 & 4.78 & 0.99 \\
\hline & $(13.83)$ & $(13.88)$ & $(14.41)$ & $(10.70)$ & $(13.08)$ & $(13.95)$ & $(2.03)$ & $(1.69)$ & $(1.74)$ \\
\hline \multicolumn{10}{|c|}{ Panel B: German students adjusted to Swiss students' characteristics } \\
\hline$Y_{C H E}$ & 441.08 & & & 431.26 & & & 512.62 & & \\
\hline \multirow{3}{*}{$\begin{array}{r}Y_{D E U} \\
\Delta_{X}\end{array}$} & 384.63 & 418.44 & 397.83 & 417.97 & 397.11 & 397.03 & 513.52 & 507.34 & 510.38 \\
\hline & & 33.82 & 13.20 & & -20.87 & -20.94 & & -6.18 & -3.14 \\
\hline & & (13.68) & $(10.50)$ & & $(9.00)$ & $(8.25)$ & & (1.28) & $(0.82)$ \\
\hline \multirow[t]{2}{*}{$\Delta_{S}$} & 56.45 & 22.64 & 43.25 & 13.29 & 34.15 & 34.22 & -0.90 & 5.28 & 2.25 \\
\hline & (13.83) & $(16.03)$ & $(13.58)$ & $(10.70)$ & (11.37) & (11.73) & $(2.03)$ & $(1.76)$ & $(1.76)$ \\
\hline \multicolumn{10}{|c|}{ Covariates } \\
\hline Other* & No & Yes & Yes & No & Yes & Yes & No & Yes & Yes \\
\hline German & No & No & No & No & Yes & Yes & No & No & No \\
\hline \multicolumn{10}{|c|}{ Observations } \\
\hline$N$ & 269 & 269 & 196 & 296 & 296 & 287 & 7,600 & 7,600 & 7,594 \\
\hline$N_{C H E}$ & 212 & 212 & 140 & 109 & 109 & 105 & 4,362 & 4,362 & 4,359 \\
\hline$N_{D E U}$ & 57 & 57 & 56 & 187 & 187 & 182 & 3,238 & 3,238 & 3,235 \\
\hline
\end{tabular}

Note: Immigrants' children are born within the country of testing and have both parents born outside of the country. Unconditional gap for immigrants' children with low parental background characteristics (1), Turkish descendants (4) and native students (both parents born in the country of testing) (7); *(2), (5) and (8) BO adjustment: uses a twofold Blinder-Oaxaca decomposition based in (2) on gender, age in month, educational level of parents categories (cat.: 1 and 2), highest occupation of the parents and number of books at home (cat.: 1 to 3) and those that do not speak German at home; (5) uses all Other covariates of Table 4; (8) uses those of (5) without the primary education category for parental schooling; In (3), (6), and (9) adjustment is performed by propensity score matching with Gaussian kernel and bandwidth 0.1 , the propensity scores are estimated by logit regression on the same covariates as in the respective BO adjustments. All standard errors given in brackets, are simulated with 500 bootstrap replications.

Source: PISA 2009, own calculations. 
Table 6: Mean gap decomposition between Swiss and German immigrants' Children reading TEST SCORES, ADJUSTED TO OTHER COUNTRIES CHARACTERISTICS

SCHOOL CHARACTERISTICS

\begin{tabular}{|c|c|c|c|c|c|c|c|c|c|c|}
\hline & \multicolumn{5}{|c|}{ BO adjustment } & \multicolumn{5}{|c|}{ Matching adjustment } \\
\hline & $(1)$ & $(2)^{*}$ & $(3)$ & $(4)$ & $(5)$ & (6) & $(7)^{*}$ & (8) & (9) & $(10)$ \\
\hline \multicolumn{11}{|c|}{ Panel A: Swiss students adjusted to German students' characteristics } \\
\hline$Y_{C H E}$ & 456.09 & 454.37 & 451.92 & 444.17 & 440.01 & 458.22 & 456.16 & 454.44 & 448.46 & 446.17 \\
\hline \multirow[t]{5}{*}{$Y_{D E U}$} & 439.05 & 442.49 & 439.05 & 439.05 & 439.05 & 439.05 & 442.49 & 439.05 & 439.05 & 439.05 \\
\hline & 1.00 & 2.72 & 5.17 & 12.92 & 17.08 & -1.13 & 0.06 & 2.66 & 8.63 & 10.93 \\
\hline & $(3.72)$ & $(4.22)$ & $(4.33)$ & $(5.40)$ & $(5.59)$ & $(3.35)$ & $(3.87)$ & $(3.45)$ & $(4.28)$ & $(3.86)$ \\
\hline & 17.05 & 11.01 & 12.88 & 5.13 & 0.97 & 19.18 & 13.67 & 15.39 & 9.42 & 7.12 \\
\hline & $(5.93)$ & $(6.02)$ & $(5.59)$ & $(4.05)$ & $(4.66)$ & $(5.74)$ & $(6.04)$ & $(5.38)$ & $(4.16)$ & $(4.92)$ \\
\hline \multicolumn{11}{|c|}{ Panel B: German students adjusted to Swiss students' characteristics } \\
\hline$Y_{C H E}$ & 457.09 & 456.22 & 457.09 & 457.09 & 457.09 & 457.09 & 456.22 & 457.09 & 457.09 & 457.09 \\
\hline \multirow[t]{5}{*}{$Y_{D E U}$} & 426.67 & 431.01 & 435.98 & 446.95 & 451.87 & 433.84 & 433.23 & 441.37 & 447.10 & 452.13 \\
\hline & -12.38 & -11.48 & -3.07 & 7.90 & 12.82 & -5.21 & -9.25 & 2.33 & 8.05 & 13.08 \\
\hline & $(5.82)$ & $(5.80)$ & $(5.58)$ & $(5.55)$ & $(5.81)$ & $(4.48)$ & $(5.44)$ & $(4.91)$ & $(5.02)$ & $(5.41)$ \\
\hline & 30.43 & 25.21 & 21.11 & 10.15 & 5.22 & 23.25 & 22.99 & 15.72 & 10.00 & 4.96 \\
\hline & $(6.58)$ & $(6.55)$ & $(6.22)$ & $(3.79)$ & $(4.52)$ & $(6.02)$ & $(6.60)$ & $(5.94)$ & $(4.45)$ & $(5.17)$ \\
\hline \multicolumn{11}{|l|}{ Covariates } \\
\hline Other & Yes & Yes & Yes & Yes & Yes & Yes & Yes & Yes & Yes & Yes \\
\hline German & Yes & Yes & Yes & Yes & Yes & Yes & Yes & Yes & Yes & Yes \\
\hline Lessons & No & Yes & No & No & No & No & Yes & No & No & No \\
\hline Prop. Mig. & No & No & Yes & No & No & No & No & Yes & No & No \\
\hline \multicolumn{11}{|l|}{ Peer quality } \\
\hline Migrants & No & No & No & Yes & No & No & No & No & Yes & No \\
\hline + Natives & No & No & No & No & Yes & No & No & No & No & Yes \\
\hline \multicolumn{11}{|l|}{ Observations } \\
\hline$N$ & 1,180 & 1,152 & 1,180 & 1,180 & 1,180 & 1,153 & 1,139 & 1,146 & 1,147 & 1,105 \\
\hline$N_{C H E}$ & 824 & 809 & 824 & 824 & 824 & 798 & 808 & 790 & 792 & 750 \\
\hline$N_{D E U}$ & 356 & 343 & 356 & 356 & 356 & 355 & 331 & 356 & 355 & 355 \\
\hline
\end{tabular}

Note: Immigrants' children are born within the country of testing and have both parents born outside of the country. (1) and (5) are the same as Columns (3) and (7) from Table 4. (2)* and (7)* include number of German lessons in school. In this decompositions the reference sample is reduced due to the inability to impute based on school level. The test score average before adjustment is 456.22 in Switzerland, 442.49 in Germany, leaving a raw gap of 13.74. (3) and (8) include the proportion of migrants in school. (4) and (9) present the average reading test score of migrants in school only, and (5) and (9) additionally include native children in school. (1) to (5) present BO adjustment. In (6) to (10), adjustment is performed by propensity score matching with Gaussian kernel and bandwidth 0.1, the propensity scores are estimated by logit regression on the same covariates as the in BO adjustment. All standard errors given in brackets, are simulated with 500 bootstrap replications.

Source: PISA 2009, own calculations. 


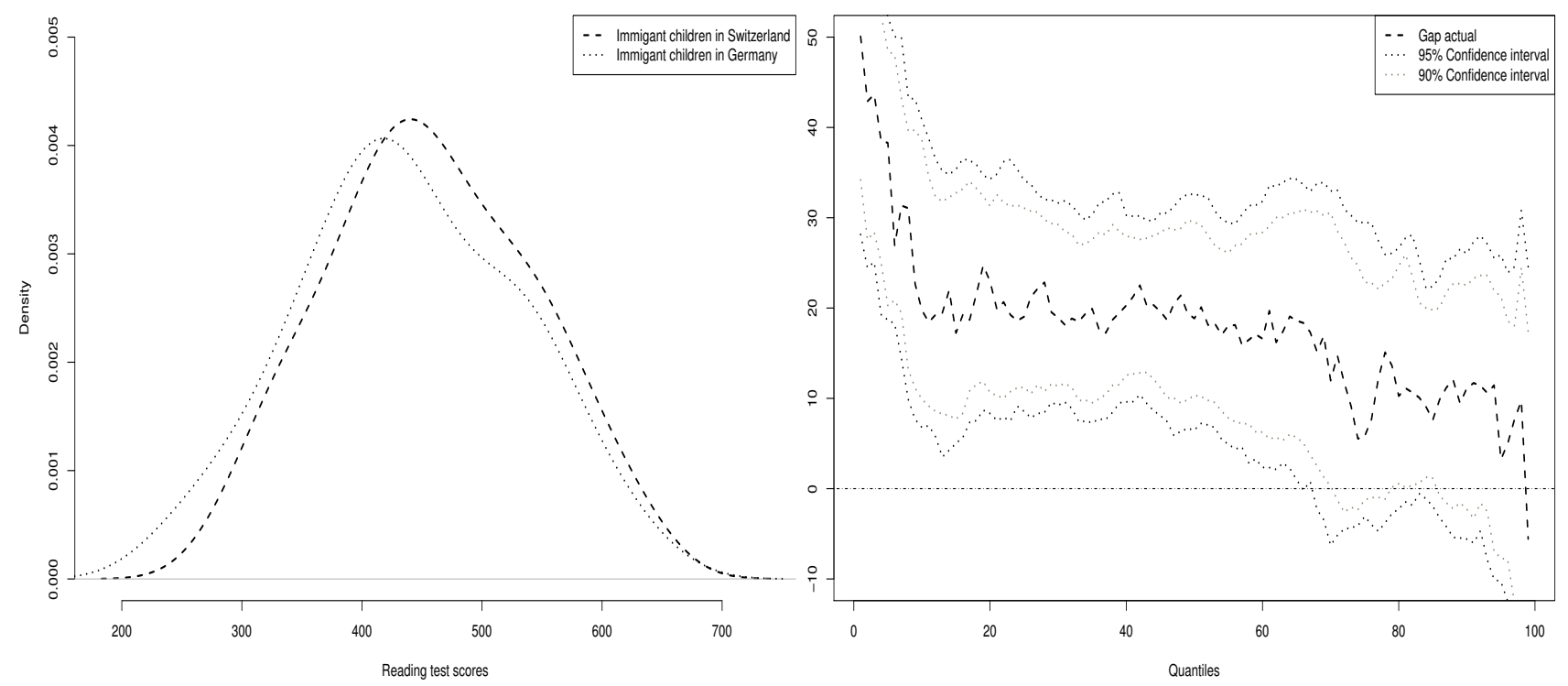

Figure 1: SECOND-GENERATION IMMIGRANTS KERNEL READING TEST SCORE DENSITIES AND UNCONDITIONAL QUANTILE GAP

Note: Left graph: Reading test score kernel densities; right graph: Quantile gap (dashed line) and bootstrapped confidence intervals (dotted lines: $90 \%$ gray; $95 \%$ black) based on 500 replications. Source: PISA 2009, own calculations 

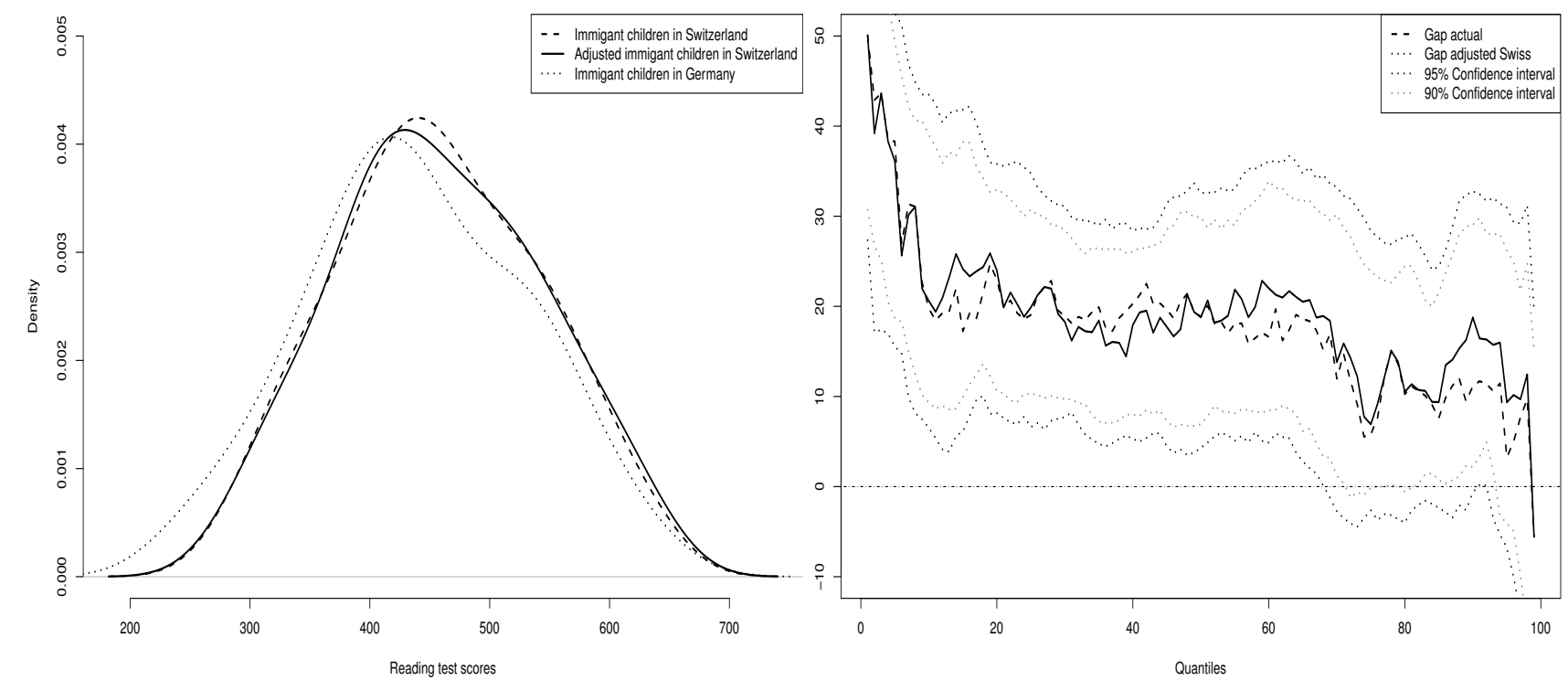

(A) Adjustment based on background characteristics and German spoken at home
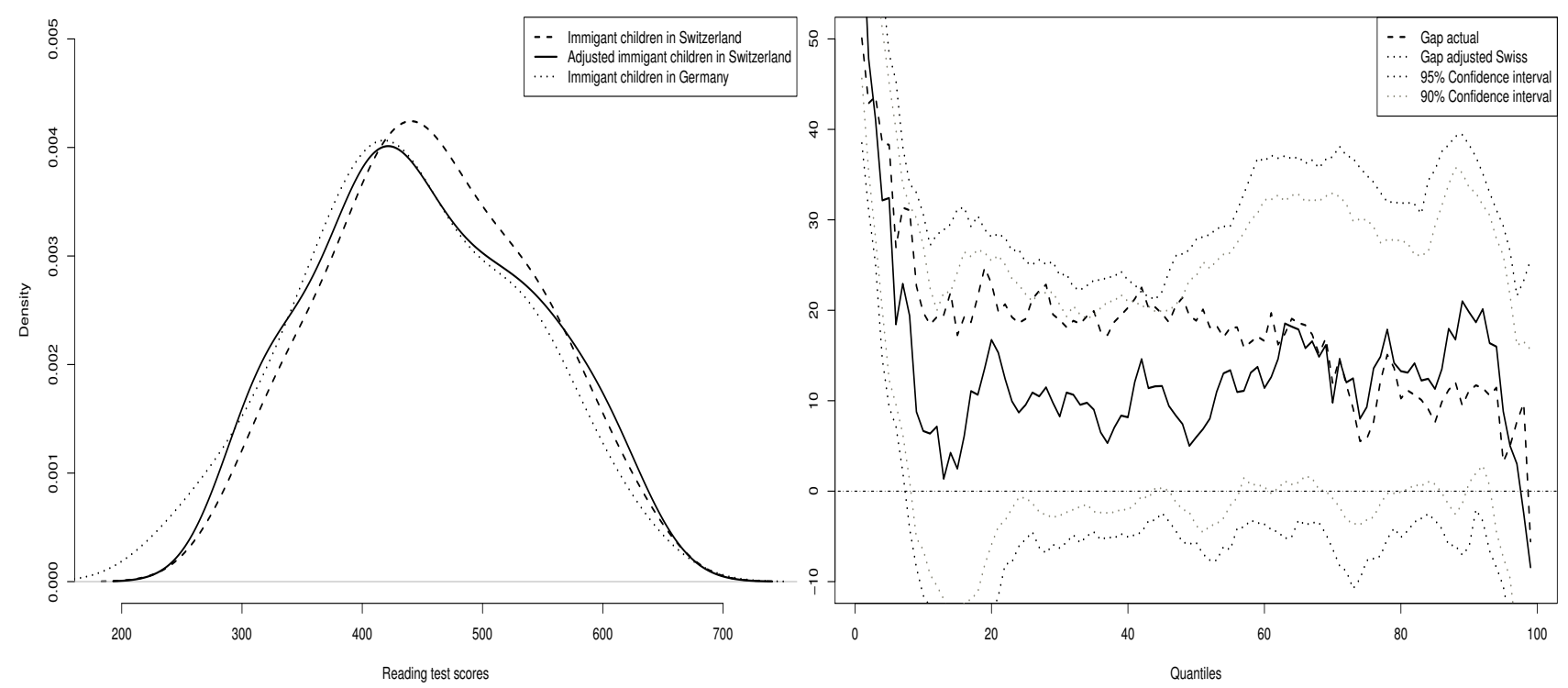

(B) Adjustment based on background characteristics, German spoken at home, and country of origin

Figure 2: SECOND-GENERATION IMMIGRANTS KERNEL READING TEST SCORE DENSITIES AND QUANTILE GAP, Swiss STUdents ADJusted to German CHARACTERISTiCs

Note: Left graph: Reading test score kernel densities; right graph: Unconditional quantile gap (dashed line), adjusted quantile gap (solid line), and bootstrapped confidence intervals for the adjusted quantile gap (dotted lines) based on 500 replications; Panel A: adjustment is performed by propensity score matching including gender, age in months, educational level of parents, highest occupation of parents, number of books at home, and German spoken at home. Panel B: Additionally includes the parents' country of origin.

Source: PISA 2009, own calculations 

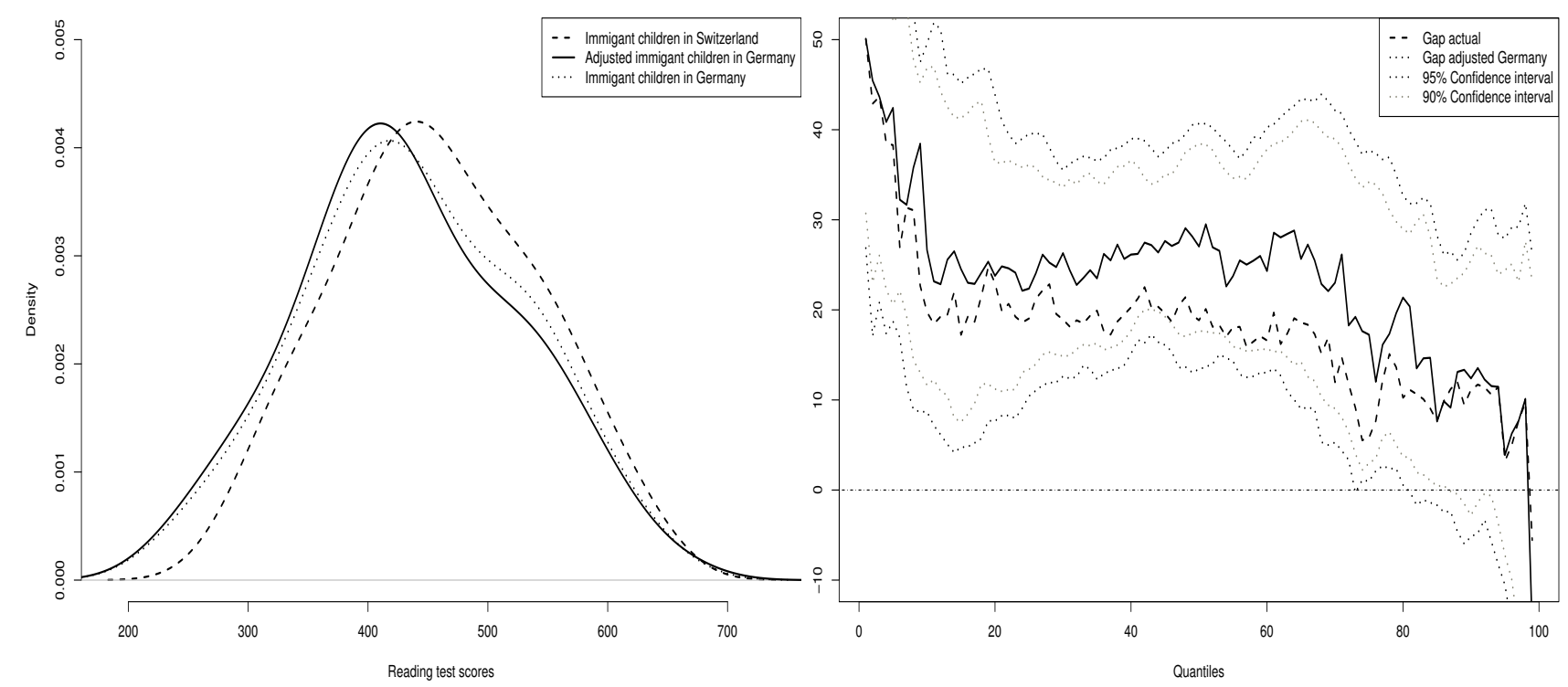

(A) Adjustment based on background characteristics and German spoken at home
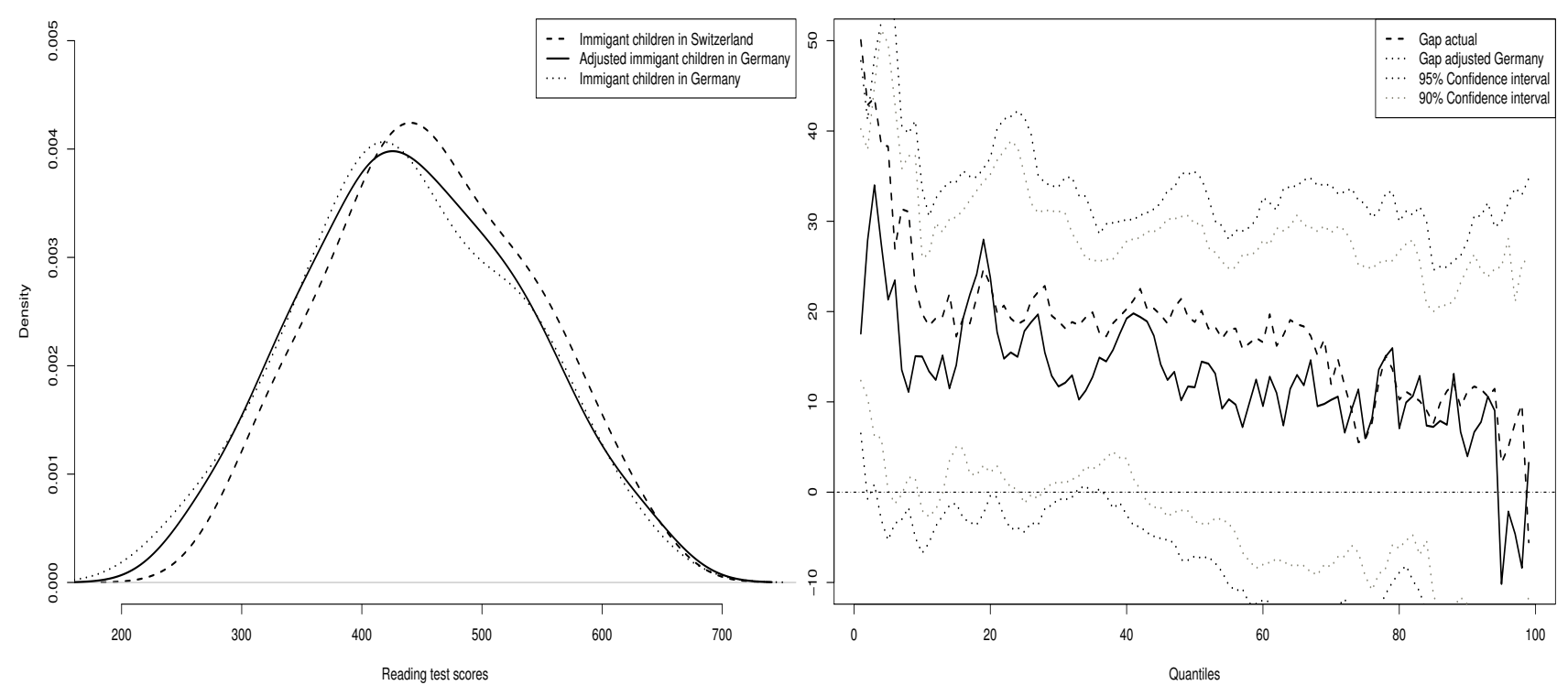

(B) Adjustment based on background characteristics, German spoken at home, and country of origin

Figure 3: SECOND-GENERATION IMMIGRANTS KERNEL READING TEST SCORE DENSITIES AND QUANTILE GAP, German Students ADJusted to Swiss CHARACTERISTiCs

Note: Left graph: Reading test score kernel densities; right graph: Unconditional quantile gap (dashed line), adjusted quantile gap (solid line), and bootstrapped confidence intervals for the adjusted quantile gap (dotted lines) based on 500 replications; Panel A: adjustment is performed by propensity score matching including gender, age in months, educational level of parents, highest occupation of parents, number of books at home, and German spoken at home. Panel B: Additionally includes the parents' country of origin.

Source: PISA 2009, own calculations 
For Online Publication

Supplementary Material:

Analyzing educational achievement differences between second-generation immigrants: Comparing Germany and German-speaking Switzerland

Johannes S. Kunz

August 22, 2014 


\section{A Math literacy}

In this Appendix, I present the analysis using math literacy scores as dependent variable (average of five Plausible Values), all other steps are equal to in the main specification. The results are highly significant economically and statistically. Qualitatively the math results confirm the reading results presented in the main text.

Table A.1: SeCond-Generation immigrant-native math test SCORE Gaps

\begin{tabular}{|c|c|c|c|c|c|c|}
\hline & \multicolumn{3}{|c|}{$\overline{\text { Overall sample }}$} & \multicolumn{3}{|c|}{ Selected sample } \\
\hline & (1) & $(2)$ & $(3)$ & (4) & $(5)$ & $(6)$ \\
\hline \multicolumn{7}{|c|}{ Panel A: Germany } \\
\hline Immigrant & $\begin{array}{c}-60.24 \\
(4.37)\end{array}$ & $\begin{array}{c}-23.09 \\
(4.24)\end{array}$ & $\begin{array}{l}-8.31 \\
(4.83)\end{array}$ & $\begin{array}{c}-76.25 \\
(5.21)\end{array}$ & $\begin{array}{r}-35.47 \\
(5.47)\end{array}$ & $\begin{array}{c}-20.23 \\
(6.51)\end{array}$ \\
\hline NObs & 3,791 & 3,791 & 3,791 & 3,632 & 3,632 & 3,632 \\
\hline
\end{tabular}

Panel B: Switzerland

\begin{tabular}{lccccccc} 
Immigrant & -62.47 & -32.74 & -22.21 & & -69.04 & -36.23 & -11.11 \\
& $(2.40)$ & $(2.44)$ & $(2.85)$ & & $(3.42)$ & $(3.46)$ & $(4.71)$ \\
NObs & 8,292 & 8,292 & 8,292 & & 5,249 & 5,249 & 5,249 \\
& & & & & & \\
& & & & & \multicolumn{3}{c}{ German-speaking without } \\
& & & & & \multicolumn{3}{c}{ Western Europeans } \\
\cline { 5 - 7 } & & & & -70.84 & -36.73 & -12.28 \\
Immigrant & & & & $(3.46)$ & $(3.56)$ & $(5.01)$ \\
NObs & & & & 5,189 & 5,189 & 5,189
\end{tabular}

Covariates

Other No Yes Yes No Yes Yes

Language No No Yes No No Yes

Note: Immigrants' children are born within the country of testing and have both parents born outside of the country. Natives' children have both parents born in the country of testing. (1) and (4) report OLS regressions of reading test scores on an Immigrant dummy; (2) and (5) additionally include individual and family background characteristics (Other); (3) and (6) add the German speaking at home indicator, each for the respective sample selection. Robust standard errors are given in brackets. NObs stands for Number of Observations.

Source: PISA 2009, own calculations. 
Table A.2: Mean gap Decomposition Between Swiss And German immigrants' Children Math TEST SCORES, ADJUSTED TO OTHER COUNTRIES CHARACTERISTICS

\begin{tabular}{|c|c|c|c|c|c|c|c|c|c|}
\hline & \multirow{2}{*}{$\begin{array}{c}\text { Actual } \\
(1)\end{array}$} & \multicolumn{4}{|c|}{ BO adjustment } & \multicolumn{4}{|c|}{ Matching adjustment } \\
\hline & & $(2)$ & $(3)$ & $(4)$ & $(5)$ & $(6)$ & $(7)$ & $(8)$ & $(9)$ \\
\hline \multicolumn{10}{|c|}{ Panel A: Swiss students adjusted to German students' characteristics } \\
\hline$Y_{C H E}$ & 484.81 & 487.14 & 484.41 & 492.58 & 490.05 & 484.58 & 487.10 & 484.55 & 484.92 \\
\hline \multirow{3}{*}{$\begin{array}{r}Y_{D E U} \\
\Delta_{X}\end{array}$} & 452.15 & & & & & & & & \\
\hline & & 2.33 & -0.40 & 7.77 & 5.24 & 0.22 & -2.30 & 0.25 & -0.12 \\
\hline & & (3.78) & $(4.02)$ & $(5.71)$ & $(5.70)$ & (3.12) & $(3.19)$ & $(5.94)$ & (5.61) \\
\hline \multirow[t]{2}{*}{$\Delta_{S}$} & 32.66 & 30.33 & 33.06 & 24.89 & 27.42 & 32.43 & 34.95 & 32.41 & 32.77 \\
\hline & (6.01) & $(6.35)$ & $(6.15)$ & $(7.17)$ & $(7.45)$ & $(5.87)$ & $(6.20)$ & $(7.47)$ & $(7.56)$ \\
\hline
\end{tabular}

Panel B: German students adjusted to Swiss students' characteristics

\begin{tabular}{|c|c|c|c|c|c|c|c|c|c|}
\hline \multirow{3}{*}{$\begin{array}{l}Y_{C H E} \\
Y_{D E U} \\
\Delta_{X}\end{array}$} & 484.81 & & & & & & & & \\
\hline & 452.15 & 442.01 & 438.11 & 436.03 & 432.04 & 449.70 & 446.23 & 451.22 & 450.49 \\
\hline & & $\begin{array}{c}-10.14 \\
(4.60)\end{array}$ & $\begin{array}{c}-14.04 \\
(5.40)\end{array}$ & $\begin{array}{c}-16.12 \\
(9.12)\end{array}$ & $\begin{array}{c}-20.11 \\
(9.40)\end{array}$ & $\begin{array}{l}-2.45 \\
(3.47)\end{array}$ & $\begin{array}{l}-5.91 \\
(4.08)\end{array}$ & $\begin{array}{l}-0.93 \\
(6.24)\end{array}$ & $\begin{array}{l}-1.66 \\
(6.55)\end{array}$ \\
\hline$\Delta_{S}$ & $\begin{array}{l}32.66 \\
(6.01)\end{array}$ & $\begin{array}{l}42.80 \\
(6.51)\end{array}$ & $\begin{array}{l}46.70 \\
(6.93)\end{array}$ & $\begin{array}{l}48.78 \\
(9.57)\end{array}$ & $\begin{array}{l}52.76 \\
(9.83)\end{array}$ & $\begin{array}{l}35.11 \\
(5.92)\end{array}$ & $\begin{array}{l}38.57 \\
(6.44)\end{array}$ & $\begin{array}{l}33.58 \\
(8.06)\end{array}$ & $\begin{array}{l}34.32 \\
(8.10)\end{array}$ \\
\hline \multicolumn{10}{|c|}{ Covariates } \\
\hline Other & No & Yes & Yes & Yes & Yes & Yes & Yes & Yes & Yes \\
\hline German & No & No & Yes & No & Yes & No & Yes & No & Yes \\
\hline Origin & No & No & No & Yes & Yes & No & No & Yes & Yes \\
\hline \multicolumn{10}{|c|}{ Number of Observations } \\
\hline$N$ & 1,180 & 1,180 & 1,180 & 1,180 & 1,180 & 1,152 & 1,153 & 1,023 & 1,037 \\
\hline$N_{C H E}$ & 824 & 824 & 824 & 824 & 824 & 797 & 798 & 668 & 682 \\
\hline$N_{D E U}$ & 356 & 356 & 356 & 356 & 356 & 355 & 355 & 355 & 355 \\
\hline
\end{tabular}

Note: Immigrants' children are born within the country of testing and have both parents born outside of the country. (1) Unconditional gap; (2) to (5) BO adjustment: uses a twofold Blinder-Oaxaca decomposition based on (2) gender, age in month, educational level of parents, highest occupation of the parents and number of books at home; (3) adds German spoken at home; (4) uses (2) and country of origin; and (5) uses (2), (3), and (4); (6) to (9) Matching adjustment is performed by propensity score matching with Gaussian kernel and bandwidth 0.1 , the propensity score is estimated by logit regression on the same covariates as in the BO adjustment. All standard errors given in brackets, are simulated with 500 bootstrap replications.

Source: PISA 2009, own calculations. 
Table A.3: Mean gap decomposition between Swiss and German children math test scores, ADJUSTED TO OTHER COUNTRIES CHARACTERISTICS

\begin{tabular}{|c|c|c|c|c|c|c|c|c|c|}
\hline & \multicolumn{3}{|c|}{ Unfavorable background } & \multicolumn{3}{|c|}{ Turkish } & \multicolumn{3}{|c|}{ Natives } \\
\hline & $(1)$ & $(2)$ & $(3)$ & $(4)$ & $(5)$ & $(6)$ & $(7)$ & $(8)$ & $(9)$ \\
\hline \multicolumn{10}{|c|}{ Panel A: Swiss students adjusted to German students' characteristics } \\
\hline$Y_{C H E}$ & 463.77 & 473.75 & 458.12 & 464.29 & 454.25 & 476.65 & 555.70 & 550.65 & 557.86 \\
\hline \multirow{3}{*}{$\begin{array}{r}Y_{D E U} \\
\Delta_{X}\end{array}$} & 414.99 & & & 434.60 & & & 529.25 & & \\
\hline & & 9.98 & 5.66 & & -10.04 & -12.37 & & -5.05 & -2.17 \\
\hline & & $(9.18)$ & $(8.49)$ & & $(11.07)$ & $(9.75)$ & & $(0.95)$ & $(0.64)$ \\
\hline \multirow[t]{2}{*}{$\Delta_{S}$} & 48.79 & 38.81 & 43.13 & 29.68 & 39.72 & 42.05 & 26.45 & 31.50 & 28.61 \\
\hline & $(11.88)$ & $(13.81)$ & $(13.29)$ & $(10.89)$ & $(12.97)$ & $(13.47)$ & $(2.08)$ & $(1.78)$ & $(1.93)$ \\
\hline \multicolumn{10}{|c|}{ Panel B: German students adjusted to Swiss students' characteristics } \\
\hline$Y_{C H E}$ & 463.77 & & & 464.29 & & & 555.70 & & \\
\hline \multirow{3}{*}{$\begin{array}{r}Y_{D E U} \\
\Delta_{X}\end{array}$} & 414.99 & 432.59 & 423.00 & 434.60 & 414.24 & 417.87 & 529.25 & 522.82 & 526.04 \\
\hline & & 17.60 & 8.01 & & -20.36 & -16.73 & & -6.43 & -3.21 \\
\hline & & (13.10) & $(8.75)$ & & $(7.82)$ & $(6.78)$ & & $(1.20)$ & $(0.83)$ \\
\hline \multirow[t]{2}{*}{$\Delta_{S}$} & 48.79 & 31.19 & 40.77 & 29.68 & 50.04 & 46.42 & 26.45 & 32.88 & 29.66 \\
\hline & $(11.88)$ & $(16.10)$ & $(11.62)$ & $(10.89)$ & $(11.41)$ & (11.48) & $(2.08)$ & $(1.89)$ & $(1.83)$ \\
\hline \multicolumn{10}{|c|}{ Covariates } \\
\hline Other* & No & Yes & Yes & No & Yes & Yes & No & Yes & Yes \\
\hline German & No & No & No & No & Yes & Yes & No & No & No \\
\hline \multicolumn{10}{|c|}{ Number of Observations } \\
\hline$N$ & 269 & 269 & 196 & 296 & 296 & 287 & 7,600 & 7,600 & 7,594 \\
\hline$N_{C H E}$ & 212 & 212 & 140 & 109 & 109 & 105 & 4,362 & 4,362 & 4,359 \\
\hline$N_{D E U}$ & 57 & 57 & 56 & 187 & 187 & 182 & 3,238 & 3,238 & 3,235 \\
\hline
\end{tabular}

Note: Immigrants' children are born within the country of testing and have both parents born outside of the country. Unconditional gap for immigrants' children with low parental background characteristics (1), Turkish descendants (4) and native students (both parents born in the country of testing) (7); *(2), (5), and (8) BO adjustment: uses a twofold Blinder-Oaxaca decomposition based in (2) on gender, age in month, educational level of parents categories (1) and (2), highest occupation of the parents and number of books at home (1) to (3) and those that do not speak German at home; (5) uses all Other covariates of Table 4; (8) uses those of (5) without the primary education category for parental schooling; (3), (6), and (9) Matching adjustment performed by propensity score matching with Gaussian kernel and bandwidth 0.1 , the propensity score is estimated by logit regression on the same covariates as in the respective BO adjustments. All standard errors given in brackets are simulated with 500 bootstrap replications.

Source: PISA 2009, own calculations. 
Table A.4: Descriptive statistics of SCHOOl CharaCteristics Visited By SECOND-Generation IMMIGRANT STUDENTS BY COUNTRY

\begin{tabular}{lrr}
\hline \hline Variables & Switzerland & Germany \\
\hline \multirow{2}{*}{ Number of } & & \\
Math lessons in school & 4.62 & 4.22 \\
& $(1.10)$ & $(1.06)$ \\
all lessons in school & {$[824]$} & {$[345]$} \\
& 33.65 & 31.81 \\
Math lessons out-of-school & $(3.44)$ & $(3.84)$ \\
& {$[809]$} & {$[343]$} \\
& 0.55 & 0.79 \\
Average math peer quality & $(1.25)$ & $(1.49)$ \\
immigrants' children in school & {$[598]$} & {$[227]$} \\
& 497.03 & 466.57 \\
+ natives in school & $(71.31)$ & $(79.41)$ \\
& 530.95 & 487.85 \\
& $(62.58)$ & $(79.13)$ \\
\hline
\end{tabular}

Note: Switzerland refers to the German-speaking part only. School level variables imputed on school level. Standard deviations are given in round and number of observations if they differ from those in the main specification (CHE: 824; DEU: 356) in squared brackets. Math lessons out-ofschool was assessed categorically, the average is taken after redefinition by the midpoint of the categories that represent hours (the highest category was 6 and more, which is coded as 6 ). The average peer quality is first estimated by using only the second-generation migrants in school and then additionally using the natives in school. These are then binned into categories of 25 test score point steps from 300 to 650 .

Source: PISA 2009, own calculations. 
Table A.5: Mean gap decomposition between Swiss and German immigrants' Children math TEST SCORES, ADJUSTED TO OTHER COUNTRIES CHARACTERISTICS

SCHOOL CHARACTERISTICS

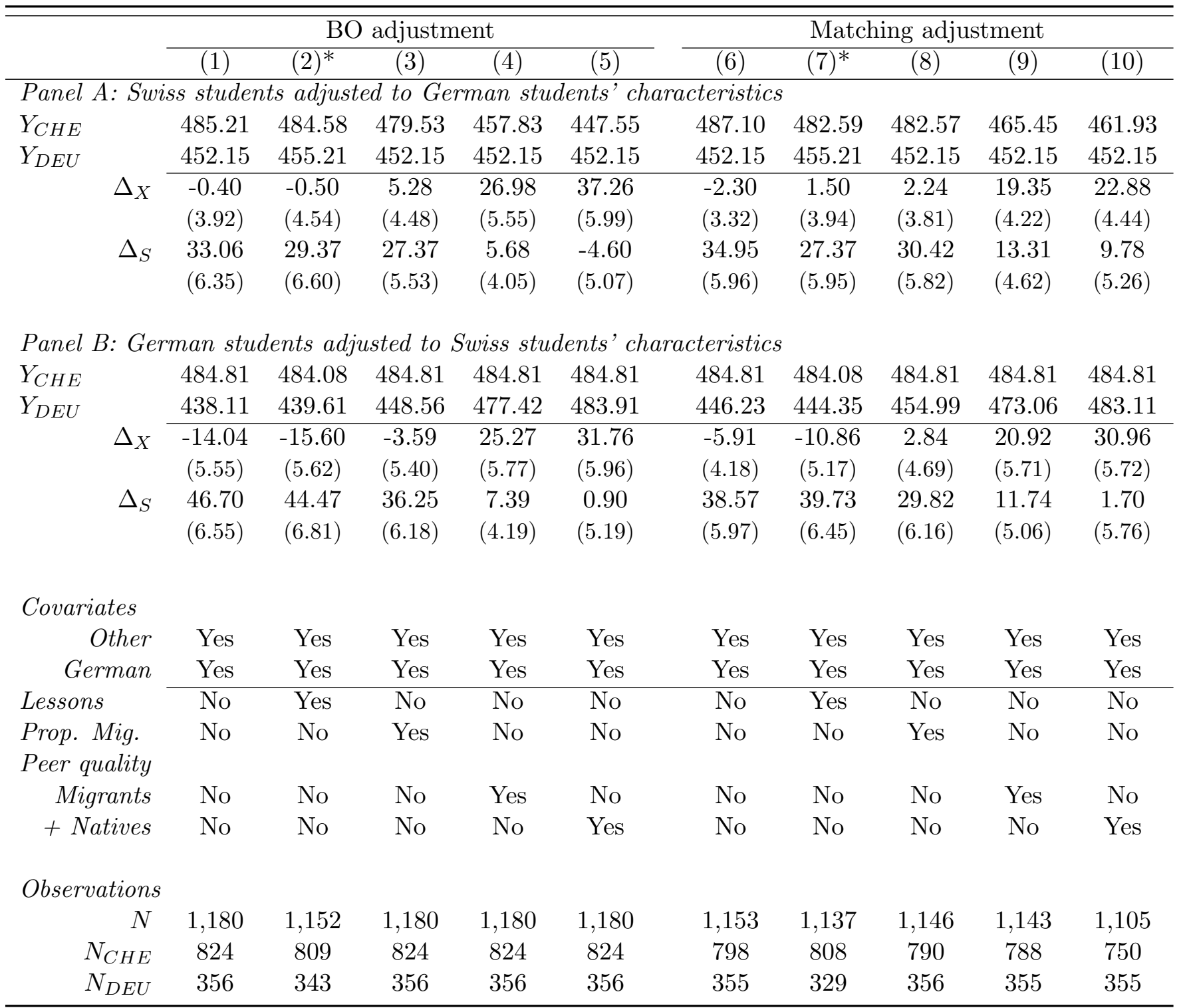

Note: Immigrants' children are born within the country of testing and have both parents born outside of the country. (1) and (5) are the same as Columns (3) and (7) from Table A.2. (2)* and (7)* include number of math lessons in school, in this decompositions the reference sample is reduced due to the inability to impute based on school level, the test score average before adjustment is 484.08 in Switzerland, 455.21 in Germany, and a raw gap of 28.87. (3) and (8) include the proportion of migrants in school. (4) and (9) the average peer reading test schore of migrants in school only, and (5) and (9) including additionally native children in school. (1) to (5) BO adjustment as described in Table 3. (6) to (10) Matching adjustment is performed by propensity score matching with Gaussian kernel and bandwidth 0.1 , the propensity score is estimated by logit regression on the same covariates as in the BO adjustment. All standard errors given in brackets, are simulated with 500 bootstrap replications.

Source: PISA 2009, own calculations. 


\section{B Robustness checks}

In this Appendix, I present the main Table 3 using reading literacy scores (average of five Plausible Values) as dependent variable. First, I include the French-, German- and Italian-speaking parts of Switzerland. Second, I present the main results for all immigrant students including Aussiedler, Albanians and Western Europeans. Third, I use sampling weights, Nearest Neighbor matching (1 and 5), and vary the bandwidth (0.095 and 0.105) of the main specification. Next, I use only the first plausible value, base the imputation mechanism on all observations within a country and use regressions (ordered probit and ordinary least squares) to predict the missing values. 
Table B.1: Mean gap decomposition Between Swiss and German immigrants' Children REAding TEST SCORES, ADJUSTED TO OTHER COUNTRIES CHARACTERISTICS:

All areas

\begin{tabular}{|c|c|c|c|c|c|c|c|c|c|}
\hline & \multirow{2}{*}{$\begin{array}{c}\text { Actual } \\
(1)\end{array}$} & \multicolumn{4}{|c|}{$\overline{\mathrm{BO} \text { adjustment }}$} & \multicolumn{4}{|c|}{ Matching adjustment } \\
\hline & & $(2)$ & $(3)$ & $(4)$ & $(5)$ & $(6)$ & $(7)$ & $(8)$ & $(9)$ \\
\hline \multicolumn{10}{|c|}{ Panel A: Swiss students adjusted to German students' characteristics } \\
\hline$Y_{C H E}$ & 460.59 & 466.99 & 467.37 & 480.38 & 480.22 & 457.71 & 457.52 & 446.90 & 446.77 \\
\hline$Y_{D E U}$ & 439.05 & & & & & & & & \\
\hline \multirow[t]{2}{*}{$\Delta_{X}$} & & 6.40 & 6.78 & 19.79 & 19.63 & 2.88 & 3.07 & 13.69 & 13.83 \\
\hline & & $(3.01)$ & $(2.65)$ & $(4.28)$ & $(4.21)$ & $(2.10)$ & $(2.08)$ & $(5.02)$ & $(5.52)$ \\
\hline \multirow[t]{2}{*}{$\Delta_{S}$} & 21.55 & 15.15 & 14.76 & 1.76 & 1.92 & 18.67 & 18.47 & 7.86 & 7.72 \\
\hline & $(5.75)$ & $(5.88)$ & $(5.27)$ & $(5.95)$ & $(5.91)$ & $(5.25)$ & $(5.37)$ & $(6.45)$ & $(7.08)$ \\
\hline
\end{tabular}

Panel B: German students adjusted to Swiss students' characteristics

$Y_{C H E} \quad 460.59$

\begin{tabular}{cccccccccc}
$Y_{D E U}$ & 439.05 & 434.74 & 435.76 & 437.09 & 437.43 & 440.14 & 440.61 & 449.06 & 449.12 \\
\cline { 2 - 10 }$\Delta_{X}$ & & -4.31 & -3.29 & -1.96 & -1.62 & 1.09 & 1.56 & 10.01 & 10.07 \\
& & $(4.81)$ & $(4.79)$ & $(7.84)$ & $(7.95)$ & $(3.34)$ & $(3.26)$ & $(6.20)$ & $(5.83)$ \\
& 21.55 & 25.86 & 24.84 & 23.51 & 23.17 & 20.46 & 19.99 & 11.54 & 11.48 \\
& $(5.75)$ & $(6.18)$ & $(6.17)$ & $(8.31)$ & $(8.53)$ & $(5.45)$ & $(5.84)$ & $(7.18)$ & $(7.43)$
\end{tabular}

$\begin{array}{clllllllll}\text { Covariates } & & & & & & & \\ \text { Other } & \text { No } & \text { Yes } & \text { Yes } & \text { Yes } & \text { Yes } & \text { Yes } & \text { Yes } & \text { Yes } & \text { Yes } \\ \text { German } & \text { No } & \text { No } & \text { Yes } & \text { No } & \text { Yes } & \text { No } & \text { Yes } & \text { No } & \text { Yes } \\ \text { Origin } & \text { No } & \text { No } & \text { No } & \text { Yes } & \text { Yes } & \text { No } & \text { No } & \text { Yes } & \text { Yes }\end{array}$

Observations

\begin{tabular}{rccccccccc}
$N$ & 1,962 & 1,962 & 1,962 & 1,962 & 1,962 & 1,940 & 1,950 & 1,742 & 1,753 \\
$N_{C H E}$ & 1,606 & 1,606 & 1,606 & 1,606 & 1,606 & 1,584 & 1,594 & 1,387 & 1,398 \\
$N_{D E U}$ & 356 & 356 & 356 & 356 & 356 & 356 & 356 & 355 & 355 \\
\hline
\end{tabular}

Note: Immigrants' children are born within the country of testing and have both parents born outside of the country. (1) Unconditional gap; (2) to (5) BO adjustment: uses a twofold Blinder-Oaxaca decomposition based on (2) gender, age in month, educational level of parents, highest occupation of the parents and number of books at home; (3) adds German spoken at home; (4) uses (2) and country of origin; and (5) uses (2), (3), and (4); (6) to (9) Matching adjustment is performed by propensity score matching with Gaussian kernel and bandwidth 0.1, the propensity score is estimated by logit regression on the same covariates as in the BO adjustment. All standard errors given in brackets, are simulated with 500 bootstrap replications.

Source: PISA 2009, own calculations. 
Table B.2: Mean gap decomposition between Swiss and German immigrants' Children Reading TEST SCORES, ADJUSTED TO OTHER COUNTRIES CHARACTERISTICS:

All migrants

\begin{tabular}{|c|c|c|c|c|c|c|c|c|c|}
\hline & \multirow{2}{*}{$\begin{array}{c}\text { Actual } \\
(1)\end{array}$} & \multicolumn{4}{|c|}{ BO adjustment } & \multicolumn{4}{|c|}{ Matching adjustment } \\
\hline & & $(2)$ & $(3)$ & $(4)$ & $(5)$ & $(6)$ & $(7)$ & $(8)$ & $(9)$ \\
\hline \multicolumn{10}{|c|}{ Panel A: Swiss students adjusted to German students' characteristics } \\
\hline$Y_{C H E}$ & 458.50 & 458.44 & 453.4 & 461.93 & 455.07 & 460.55 & 463.60 & 457.65 & 459.88 \\
\hline \multirow{3}{*}{$\begin{array}{r}Y_{D E U} \\
\Delta_{X}\end{array}$} & 454.39 & & & & & & & & \\
\hline & & -0.06 & -5.10 & 3.43 & -0.61 & -2.05 & -5.10 & 0.85 & -1.38 \\
\hline & & $(3.16)$ & $(3.68)$ & $(4.31)$ & $(4.38)$ & $(2.70)$ & $(2.96)$ & $(4.56)$ & $(4.48)$ \\
\hline \multirow[t]{2}{*}{$\Delta_{S}$} & 4.11 & 4.17 & 9.21 & 0.68 & 4.72 & 6.16 & 9.21 & 3.26 & 5.49 \\
\hline & $(5.21)$ & $(5.20)$ & (5.09) & $(5.62)$ & $(5.25)$ & $(5.35)$ & $(5.21)$ & $(5.94)$ & $(5.85)$ \\
\hline
\end{tabular}

Panel B: German students adjusted to Swiss students' characteristics

$Y_{C H E} \quad 458.50$

\begin{tabular}{cccccccccc}
$Y_{D E U}$ & 454.39 & 441.16 & 434.22 & 443.42 & 438.40 & 447.88 & 442.68 & 455.32 & 452.22 \\
\cline { 2 - 10 }$\Delta_{X}$ & & -13.23 & -20.17 & -10.97 & -16.35 & -6.51 & -11.71 & 0.93 & -2.17 \\
& & $(4.35)$ & $(4.57)$ & $(7.53)$ & $(7.66)$ & $(3.60)$ & $(3.61)$ & $(5.57)$ & $(5.95)$ \\
$\Delta_{S}$ & 4.11 & 17.34 & 24.28 & 15.09 & 20.46 & 10.62 & 15.82 & 3.18 & 6.28 \\
& $(5.21)$ & $(5.54)$ & $(5.34)$ & $(8.19)$ & $(8.34)$ & $(5.37)$ & $(5.38)$ & $(6.50)$ & $(6.75)$
\end{tabular}

\begin{tabular}{|c|c|c|c|c|c|c|c|c|c|}
\hline \multicolumn{10}{|c|}{ Covariates } \\
\hline Other & No & Yes & Yes & Yes & Yes & Yes & Yes & Yes & Yes \\
\hline German & No & No & Yes & No & Yes & No & Yes & No & Yes \\
\hline Origin & No & No & No & Yes & Yes & No & No & Yes & Yes \\
\hline \multicolumn{10}{|c|}{ Observations } \\
\hline$N$ & 1,399 & 1,399 & 1,399 & 1,399 & 1,399 & 1,373 & 1,375 & 1,261 & 1,274 \\
\hline$N_{C H E}$ & 884 & 884 & 884 & 884 & 884 & 859 & 863 & 747 & 760 \\
\hline$N_{D E U}$ & 515 & 515 & 515 & 515 & 515 & 514 & 512 & 514 & 514 \\
\hline
\end{tabular}

Note: Immigrants' children are born within the country of testing and have both parents born outside of the country. (1) Unconditional gap; (2) to (5) BO adjustment: uses a twofold Blinder-Oaxaca decomposition based on (2) gender, age in month, educational level of parents, highest occupation of the parents and number of books at home; (3) adds German spoken at home; (4) uses (2) and country of origin and (5) uses (2), (3), and (4); (6) to (9) Matching adjustment is performed by propensity score matching with Gaussian kernel and bandwidth 0.1, the propensity score is estimated by logit regression on the same covariates as in the BO adjustment. All standard errors given in brackets, are simulated with 500 bootstrap replications.

Source: PISA 2009, own calculations. 
Table B.3: Mean gap decomposition between Swiss and German immigrants' Children Reading TEST SCORES, ADJUSTED TO OTHER COUNTRIES CHARACTERISTICS:

\section{Sampling weights}

\begin{tabular}{|c|c|c|c|c|c|c|c|c|c|}
\hline & \multirow{2}{*}{$\begin{array}{c}\text { Actual } \\
(1)\end{array}$} & \multicolumn{4}{|c|}{ BO adjustment } & \multicolumn{4}{|c|}{ Matching adjustment } \\
\hline & & $(2)$ & $(3)$ & $(4)$ & $(5)$ & $(6)$ & $(7)$ & $(8)$ & $(9)$ \\
\hline \multicolumn{10}{|c|}{ Panel A: Swiss students adjusted to German students' characteristics } \\
\hline$Y_{C H E}$ & 456.60 & 462.12 & 458.81 & 475.44 & 472.38 & 455.84 & 458.58 & 451.29 & 452.45 \\
\hline$Y_{D E U}$ & 441.42 & & & & & & & & \\
\hline$\Delta_{X}$ & & 5.52 & 2.21 & 18.84 & 15.78 & 0.77 & -1.98 & 5.31 & 4.16 \\
\hline & & $(4.20)$ & $(4.34)$ & $(5.59)$ & $(5.69)$ & (4.01) & $(3.97)$ & $(6.37)$ & $(6.50)$ \\
\hline$\Delta_{S}$ & $\begin{array}{l}15.18 \\
(5.83)\end{array}$ & $\begin{array}{c}9.66 \\
(6.28)\end{array}$ & $\begin{array}{l}12.97 \\
(6.31)\end{array}$ & $\begin{array}{l}-3.66 \\
(7.07)\end{array}$ & $\begin{array}{c}-0.60 \\
(7.10)\end{array}$ & $\begin{array}{l}14.41 \\
(5.74)\end{array}$ & $\begin{array}{l}17.16 \\
(5.59)\end{array}$ & $\begin{array}{c}9.87 \\
(7.73)\end{array}$ & $\begin{array}{l}11.02 \\
(7.31)\end{array}$ \\
\hline
\end{tabular}

Panel B: German students adjusted to Swiss students' characteristics

$Y_{C H E} \quad 456.60$

\begin{tabular}{cccccccccc}
$Y_{D E U}$ & 441.42 & 432.64 & 429.34 & 436.79 & 433.73 & 437.90 & 433.66 & 444.84 & 443.73 \\
\cline { 2 - 10 }$\Delta_{X}$ & & -8.78 & -12.08 & -4.63 & -7.69 & -3.52 & -7.77 & 3.42 & 2.30 \\
& & $(5.06)$ & $(5.26)$ & $(8.87)$ & $(8.92)$ & $(4.50)$ & $(4.66)$ & $(6.75)$ & $(6.93)$ \\
$\Delta_{S}$ & 15.18 & 23.96 & 27.26 & 19.81 & 22.87 & 18.70 & 22.95 & 11.76 & 12.88 \\
& $(5.83)$ & $(6.66)$ & $(6.75)$ & $(9.75)$ & $(9.76)$ & $(6.95)$ & $(6.88)$ & $(7.88)$ & $(7.83)$
\end{tabular}

$\begin{array}{clllllllll}\text { Covariates } & & & & & & & \\ \text { Other } & \text { No } & \text { Yes } & \text { Yes } & \text { Yes } & \text { Yes } & \text { Yes } & \text { Yes } & \text { Yes } & \text { Yes } \\ \text { German } & \text { No } & \text { No } & \text { Yes } & \text { No } & \text { Yes } & \text { No } & \text { Yes } & \text { No } & \text { Yes } \\ \text { Origin } & \text { No } & \text { No } & \text { No } & \text { Yes } & \text { Yes } & \text { No } & \text { No } & \text { Yes } & \text { Yes }\end{array}$

\begin{tabular}{rccccccccc}
\multicolumn{1}{l}{ Observations } & & & & & & & & \\
$N$ & 1,180 & 1,180 & 1,180 & 1,180 & 1,180 & 1,152 & 1,153 & 1,023 & 1,037 \\
$N_{C H E}$ & 824 & 824 & 824 & 824 & 824 & 797 & 798 & 668 & 682 \\
$N_{D E U}$ & 356 & 356 & 356 & 356 & 356 & 355 & 355 & 355 & 355
\end{tabular}

Note: Immigrants' children are born within the country of testing and have both parents born outside of the country. (1) Unconditional gap; (2) to (5) BO adjustment: uses a twofold Blinder-Oaxaca decomposition based on (2) gender, age in month, educational level of parents, highest occupation of the parents and number of books at home; (3) adds German spoken at home; (4) uses (2) and country of origin; and (5) uses (2), (3), and (4); (6) to (9) Matching adjustment is performed by propensity score matching with Gaussian kernel and bandwidth 0.1, the propensity score is estimated by logit regression on the same covariates as in the BO adjustment. All standard errors given in brackets, are simulated with 500 bootstrap replications.

Source: PISA 2009, own calculations. 
Table B.4: Mean gap Decomposition between Swiss and German immigrants' Children Reading TEST SCORES, ADJUSTED TO OTHER COUNTRIES CHARACTERISTICS:

\section{Nearest Neighbor matching}

\begin{tabular}{|c|c|c|c|c|c|c|c|c|c|}
\hline & \multirow{2}{*}{$\begin{array}{c}\text { Actual } \\
(1)\end{array}$} & \multicolumn{4}{|c|}{ Matching adjustment (1:1) } & \multicolumn{4}{|c|}{ Matching adjustment (1:5) } \\
\hline & & $(2)$ & $(3)$ & $(4)$ & $(5)$ & $(6)$ & (7) & $(8)$ & $(9)$ \\
\hline \multicolumn{10}{|c|}{ Panel A: Swiss students adjusted to German students' characteristics } \\
\hline$Y_{C H E}$ & 457.09 & 472.49 & 450.13 & 457.67 & 476.84 & 453.29 & 460.30 & 451.73 & 453.72 \\
\hline \multirow{3}{*}{$\begin{array}{l}Y_{D E U} \\
\Delta_{X}\end{array}$} & 439.05 & & & & & & & & \\
\hline & & 15.40 & -6.96 & 0.58 & 19.75 & 3.80 & -3.21 & 5.36 & 3.38 \\
\hline & & $(8.76)$ & $(9.22)$ & $(10.76)$ & $(10.96)$ & (6.32) & $(6.18)$ & & $(8.23)$ \\
\hline \multirow[t]{2}{*}{$\Delta_{S}$} & 18.05 & 2.64 & 25.01 & 17.47 & -1.71 & 14.25 & 21.26 & 12.69 & 14.67 \\
\hline & (6.11) & $(9.55)$ & $(9.72)$ & (11.19) & (11.17) & $(7.39)$ & $(7.56)$ & $(8.67)$ & $(9.69)$ \\
\hline
\end{tabular}

Panel B: German students adjusted to Swiss students' characteristics

\begin{tabular}{cccccccccc}
$Y_{C H E}$ & 457.09 & & & & & & & & \\
$Y_{D E U}$ & 439.05 & 433.61 & 426.89 & 443.77 & 457.31 & 434.22 & 429.14 & 445.48 & 447.92 \\
\cline { 2 - 10 }$\Delta_{X}$ & & -5.44 & -12.16 & 4.73 & 18.26 & -4.82 & -9.90 & 6.44 & 8.87 \\
& & $(9.50)$ & $(9.22)$ & $(13.48)$ & $(15.01)$ & $(6.92)$ & $(7.38)$ & $(11.39)$ & $(13.28)$ \\
$\Delta_{S}$ & 18.05 & 23.49 & 30.20 & 13.32 & -0.22 & 22.87 & 27.95 & 11.61 & 9.17 \\
& $(6.11)$ & $(8.71)$ & $(9.11)$ & $(13.32)$ & $(14.41)$ & $(7.58)$ & $(8.06)$ & $(11.65)$ & $(13.41)$
\end{tabular}

$\begin{array}{clllllllll}\begin{array}{c}\text { Covariates } \\ \text { Other }\end{array} & \text { No } & \text { Yes } & \text { Yes } & \text { Yes } & \text { Yes } & \text { Yes } & \text { Yes } & \text { Yes } & \text { Yes } \\ \text { German } & \text { No } & \text { No } & \text { Yes } & \text { No } & \text { Yes } & \text { No } & \text { Yes } & \text { No } & \text { Yes } \\ \text { Origin } & \text { No } & \text { No } & \text { No } & \text { Yes } & \text { Yes } & \text { No } & \text { No } & \text { Yes } & \text { Yes }\end{array}$

\begin{tabular}{rccccccccc}
\multicolumn{1}{l}{ Observations } \\
$N$ & 1,180 & 1,152 & 1,153 & 1,023 & 1,037 & 1,152 & 1,153 & 1,023 & 1,037 \\
$N_{C H E}$ & 824 & 797 & 798 & 668 & 682 & 797 & 798 & 668 & 682 \\
$N_{D E U}$ & 356 & 355 & 355 & 355 & 355 & 355 & 355 & 355 & 355
\end{tabular}

Note: Immigrants' children are born within the country of testing and have both parents born outside of the country. (1) Unconditional gap; (2) to (9) Matching adjustment is performed by propensity score matching with Nearest Neighbor matching with 1 neighbor in (2) to (5) and 5 in (6) to (9), the propensity score is estimated by logit regression on gender, age in month, educational level of parents, highest occupation of the parents and number of books at home in (2) and (5); (3) and (6) adds German spoken at home; (4) and (7) uses (2) and country of originand (5) and (9) uses (2), (3), and (4); All standard errors given in brackets, are simulated with 500 bootstrap replications. Note that bootstrapping is not valid in the Nearest Neighbor approach. However for comparison reasons I stick to procedure.

Source: PISA 2009, own calculations. 
Table B.5: Mean gap Decomposition between Swiss and German immigrants' Children Reading TEST SCORES, ADJUSTED TO OTHER COUNTRIES CHARACTERISTICS:

Bandwidth

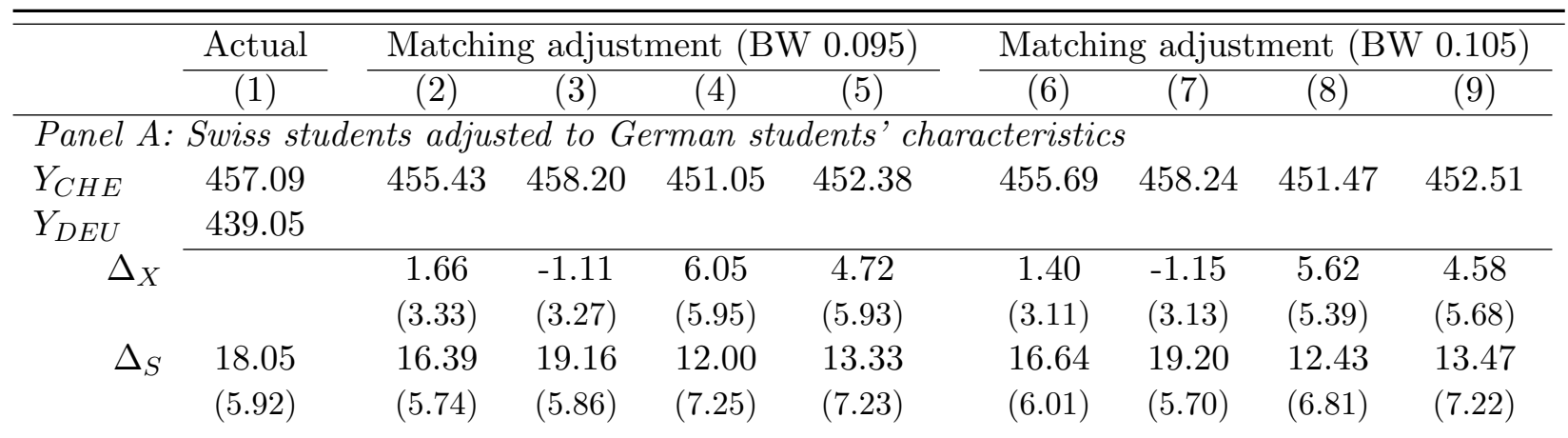

Panel B: German students adjusted to Swiss students' characteristics

$Y_{C H E} \quad 457.09$

\begin{tabular}{cccccccccc}
$Y_{D E U}$ & 439.05 & 437.75 & 433.64 & 444.90 & 444.16 & 438.23 & 434.04 & 444.60 & 443.77 \\
\cline { 2 - 9 }$\Delta_{X}$ & & -1.29 & -5.41 & 5.86 & 5.11 & -0.81 & -5.01 & 5.55 & 4.72 \\
& & $(4.07)$ & $(4.22)$ & $(7.00)$ & $(7.20)$ & $(3.75)$ & $(4.26)$ & $(6.85)$ & $(6.99)$ \\
$\Delta_{S}$ & 18.05 & 19.34 & 23.46 & 12.19 & 12.93 & 18.86 & 23.05 & 12.50 & 13.33 \\
& $(5.92)$ & $(6.02)$ & $(6.08)$ & $(7.87)$ & $(8.09)$ & $(6.41)$ & $(6.44)$ & $(7.97)$ & $(7.86)$
\end{tabular}

\begin{tabular}{|c|c|c|c|c|c|c|c|c|c|}
\hline \multicolumn{10}{|c|}{ Covariates } \\
\hline Other & No & Yes & Yes & Yes & Yes & Yes & Yes & Yes & Yes \\
\hline German & No & No & Yes & No & Yes & No & Yes & No & Yes \\
\hline Origin & No & No & No & Yes & Yes & No & No & Yes & Yes \\
\hline \multicolumn{10}{|c|}{ Observations } \\
\hline$N$ & 1,180 & 1,152 & 1,153 & 1,023 & 1,037 & 1,152 & 1,153 & 1,023 & 1,037 \\
\hline$N_{C H E}$ & 824 & 797 & 798 & 668 & 682 & 797 & 798 & 668 & 682 \\
\hline$N_{D E U}$ & 356 & 355 & 355 & 355 & 355 & 355 & 355 & 355 & 355 \\
\hline
\end{tabular}

Note: Immigrants' children are born within the country of testing and have both parents born outside of the country. (1) Unconditional gap; (2) to (9) Matching adjustment is performed by propensity score matching with Nearest Neighbor matching with 1 neighbor in (2) to (5) and 5 in (6) to (9), the propensity score is estimated by logit regression on gender, age in month, educational level of parents, highest occupation of the parents and number of books at home in (2) and (5); (3) and (6) adds German spoken at home; (4) and (7) uses (2) and country of originand (5) and (9) uses (2), (3), and (4); All standard errors given in brackets, are simulated with 500 bootstrap replications.

Source: PISA 2009, own calculations. 
Table B.6: Mean gap Decomposition Between Swiss and German immigrants' Children Reading TEST SCORES, ADJUSTED TO OTHER COUNTRIES CHARACTERISTICS:

Plausible Value 1

\begin{tabular}{|c|c|c|c|c|c|c|c|c|c|}
\hline & \multirow{2}{*}{$\begin{array}{c}\text { Actual } \\
(1)\end{array}$} & \multicolumn{4}{|c|}{ BO adjustment } & \multicolumn{4}{|c|}{ Matching adjustment } \\
\hline & & $(2)$ & $(3)$ & $(4)$ & $(5)$ & $(6)$ & $(7)$ & $(8)$ & $(9)$ \\
\hline \multicolumn{10}{|c|}{ Panel A: Swiss students adjusted to German students' characteristics } \\
\hline$Y_{C H E}$ & 455.31 & 451.66 & 454.62 & 444.28 & 446.92 & 454.15 & 456.73 & 449.20 & 450.42 \\
\hline \multirow{3}{*}{$\begin{array}{l}Y_{D E U} \\
\Delta_{X}\end{array}$} & 438.41 & & & & & & & & \\
\hline & & 3.65 & 0.69 & 11.03 & 8.39 & 1.16 & -1.43 & 6.11 & 4.89 \\
\hline & & $(3.65)$ & $(4.01)$ & $(5.51)$ & $(5.68)$ & (3.10) & $(3.27)$ & $(5.84)$ & (5.56) \\
\hline \multirow[t]{2}{*}{$\Delta_{S}$} & 16.89 & 13.24 & 16.21 & 5.86 & 8.51 & 15.73 & 18.32 & 10.79 & 12.01 \\
\hline & $(5.89)$ & $(6.23)$ & $(5.85)$ & $(6.90)$ & $(7.31)$ & $(5.81)$ & $(5.92)$ & $(7.39)$ & $(7.31)$ \\
\hline
\end{tabular}

Panel B: German students adjusted to Swiss students' characteristics

$Y_{C H E} \quad 455.31$

\begin{tabular}{cccccccccc}
$Y_{D E U}$ & 438.41 & 428.32 & 424.42 & 435.46 & 431.50 & 435.75 & 431.47 & 444.31 & 442.88 \\
\cline { 2 - 10 }$\Delta_{X}$ & & -10.09 & -13.99 & -2.95 & -6.91 & -2.66 & -6.94 & 5.89 & 4.47 \\
& & $(4.93)$ & $(5.61)$ & $(9.29)$ & $(9.98)$ & $(3.88)$ & $(4.42)$ & $(7.05)$ & $(7.22)$ \\
$\Delta_{S}$ & 16.89 & 26.98 & 30.88 & 19.84 & 23.80 & 19.55 & 23.83 & 11.00 & 12.43 \\
& $(5.89)$ & $(6.72)$ & $(7.08)$ & $(9.76)$ & $(10.42)$ & $(6.18)$ & $(6.47)$ & $(8.55)$ & $(8.12)$
\end{tabular}

$\begin{array}{clllllllll}\begin{array}{c}\text { Covariates } \\ \text { Other }\end{array} & \text { No } & \text { Yes } & \text { Yes } & \text { Yes } & \text { Yes } & \text { Yes } & \text { Yes } & \text { Yes } & \text { Yes } \\ \text { German } & \text { No } & \text { No } & \text { Yes } & \text { No } & \text { Yes } & \text { No } & \text { Yes } & \text { No } & \text { Yes } \\ \text { Origin } & \text { No } & \text { No } & \text { No } & \text { Yes } & \text { Yes } & \text { No } & \text { No } & \text { Yes } & \text { Yes }\end{array}$

\begin{tabular}{rccccccccc}
\multicolumn{2}{l}{ Observations } \\
$N$ & 1,180 & 1,180 & 1,180 & 1,180 & 1,180 & 1,152 & 1,153 & 1,023 & 1,037 \\
$N_{C H E}$ & 824 & 824 & 824 & 824 & 824 & 797 & 798 & 668 & 682 \\
$N_{D E U}$ & 356 & 356 & 356 & 356 & 356 & 355 & 355 & 355 & 355 \\
\hline
\end{tabular}

Note: Immigrants' children are born within the country of testing and have both parents born outside of the country. Instead of the main specification where the average of five Plausible Values is used, I present here the analysis based on only the first Plausible Value. (1) Unconditional gap; (2) to (5) BO adjustment: uses a twofold Blinder-Oaxaca decomposition based on (2) gender, age in month, educational level of parents, highest occupation of the parents and number of books at home; (3) adds German spoken at home; (4) uses (2) and country of origin; and (5) uses (2), (3), and (4); (6) to (9) Matching adjustment is performed by propensity score matching with Gaussian kernel and bandwidth 0.1 , the propensity score is estimated by logit regression on the same covariates as in the BO adjustment. All standard errors given in brackets, are simulated with 500 bootstrap replications.

Source: PISA 2009, own calculations. 
Table B.7: Mean gap Decomposition Between Swiss and German immigrants' Children Reading TEST SCORES, ADJUSTED TO OTHER COUNTRIES CHARACTERISTICS:

Imputation on country level

\begin{tabular}{|c|c|c|c|c|c|c|c|c|c|}
\hline & \multirow{2}{*}{$\begin{array}{c}\text { Actual } \\
(1)\end{array}$} & \multicolumn{4}{|c|}{ Matching adjustment } & \multicolumn{4}{|c|}{ Matching adjustment } \\
\hline & & $(2)$ & $(3)$ & $(4)$ & $(5)$ & $(6)$ & $(7)$ & $(8)$ & $(9)$ \\
\hline \multicolumn{10}{|c|}{ Panel A: Swiss students adjusted to German students' characteristics } \\
\hline$Y_{C H E}$ & 457.09 & 452.03 & 454.94 & 444.60 & 447.27 & 454.42 & 456.92 & 449.82 & 450.04 \\
\hline$Y_{D E U}$ & 439.05 & & & & & & & & \\
\hline$\Delta_{X}$ & & 5.06 & 2.15 & 12.49 & 9.82 & 2.67 & 0.17 & 7.27 & 7.06 \\
\hline$\Delta_{S}$ & $\begin{array}{l}18.05 \\
(5.78)\end{array}$ & $\begin{array}{l}12.99 \\
(6.20)\end{array}$ & $\begin{array}{l}15.90 \\
(5.81)\end{array}$ & $\begin{array}{c}5.56 \\
(6.84)\end{array}$ & $\begin{array}{c}8.22 \\
(7.22)\end{array}$ & $\begin{array}{l}15.38 \\
(5.88)\end{array}$ & $\begin{array}{l}17.88 \\
(5.99)\end{array}$ & $\begin{array}{l}10.77 \\
(7.57)\end{array}$ & $\begin{array}{l}10.99 \\
(7.48)\end{array}$ \\
\hline
\end{tabular}

Panel B: German students adjusted to Swiss students' characteristics

\begin{tabular}{cccccccccc}
$Y_{C H E}$ & 457.09 & & & & & & & & \\
$Y_{D E U}$ & 439.05 & 439.10 & 435.2 & 444.57 & 440.78 & 441.77 & 438.64 & 449.60 & 447.84 \\
\cline { 2 - 9 }$\Delta_{X}$ & & 0.05 & -3.85 & 5.52 & 1.73 & 2.73 & -0.40 & 10.56 & 8.79 \\
& & $(5.40)$ & $(5.96)$ & $(9.60)$ & $(10.05)$ & $(4.26)$ & $(4.62)$ & $(6.81)$ & $(6.77)$ \\
$\Delta_{S}$ & 18.05 & 18.00 & 21.90 & 12.53 & 16.32 & 15.32 & 18.45 & 7.49 & 9.26 \\
& $(5.78)$ & $(6.74)$ & $(7.02)$ & $(9.93)$ & $(10.16)$ & $(6.18)$ & $(6.50)$ & $(8.02)$ & $(7.65)$
\end{tabular}

$\begin{array}{clllllllll}\begin{array}{c}\text { Covariates } \\ \text { Other }\end{array} & \text { No } & \text { Yes } & \text { Yes } & \text { Yes } & \text { Yes } & \text { Yes } & \text { Yes } & \text { Yes } & \text { Yes } \\ \text { German } & \text { No } & \text { No } & \text { Yes } & \text { No } & \text { Yes } & \text { No } & \text { Yes } & \text { No } & \text { Yes } \\ \text { Origin } & \text { No } & \text { No } & \text { No } & \text { Yes } & \text { Yes } & \text { No } & \text { No } & \text { Yes } & \text { Yes }\end{array}$

\begin{tabular}{rccccccccc}
\multicolumn{2}{l}{ Observations } \\
$N$ & 1,180 & 1,180 & 1,180 & 1,180 & 1,180 & 1,144 & 1,132 & 997 & 970 \\
$N_{C H E}$ & 824 & 824 & 824 & 824 & 824 & 790 & 777 & 642 & 614 \\
$N_{D E U}$ & 356 & 356 & 356 & 356 & 356 & 354 & 355 & 355 & 356
\end{tabular}

Note: Immigrants' children are born within the country of testing and have both parents born outside of the country. Instead of using the children in school to impute missing values I use all children in the country. (1) Unconditional gap; (2) to (5) BO adjustment: uses a twofold Blinder-Oaxaca decomposition based on (2) gender, age in month, educational level of parents, highest occupation of the parents and number of books at home; (3) adds German spoken at home; (4) uses (2) and country of origin; and (5) uses (2), (3), and (4); (6) to (9) Matching adjustment is performed by propensity score matching with Gaussian kernel and bandwidth 0.1, the propensity score is estimated by logit regression on the same covariates as in the BO adjustment. All standard errors given in brackets, are simulated with 500 bootstrap replications.

Source: PISA 2009, own calculations. 
Table B.8: Mean gap decomposition Between Swiss and German immigrants' Children REAding TEST SCORES, ADJUSTED TO OTHER COUNTRIES CHARACTERISTICS:

Regression based imputation

\begin{tabular}{|c|c|c|c|c|c|c|c|c|c|}
\hline & \multirow{2}{*}{$\begin{array}{c}\text { Actual } \\
(1)\end{array}$} & \multicolumn{4}{|c|}{ BO adjustment } & \multicolumn{4}{|c|}{ Matching adjustment } \\
\hline & & $(2)$ & $(3)$ & $(4)$ & $(5)$ & $(6)$ & $(7)$ & $(8)$ & $(9)$ \\
\hline \multicolumn{10}{|c|}{ Panel A: Swiss students adjusted to German students' characteristics } \\
\hline$Y_{C H E}$ & 457.09 & 453.73 & 455.59 & 446.13 & 447.17 & 457.09 & 459.03 & 452.97 & 452.94 \\
\hline \multirow{3}{*}{$\begin{array}{r}Y_{D E U} \\
\Delta_{X}\end{array}$} & 439.05 & & & & & & & & \\
\hline & & 3.36 & 1.50 & 10.96 & 9.92 & 0.00 & -1.93 & 4.13 & 4.15 \\
\hline & & $(3.79)$ & $(3.96)$ & $(5.58)$ & (5.61) & (3.23) & $(3.42)$ & $(5.83)$ & $(5.66)$ \\
\hline \multirow[t]{2}{*}{$\Delta_{S}$} & 18.05 & 14.69 & 16.54 & 7.08 & 8.13 & 18.04 & 19.98 & 13.92 & 13.89 \\
\hline & (5.78) & (6.08) & $(5.86)$ & $(6.96)$ & (7.19) & $(5.86)$ & $(5.82)$ & $(7.29)$ & $(7.26)$ \\
\hline
\end{tabular}

Panel B: German students adjusted to Swiss students' characteristics

$Y_{C H E} \quad 457.09$

\begin{tabular}{cccccccccc}
$Y_{D E U}$ & 439.05 & 433.74 & 429.97 & 439.55 & 437.09 & 441.76 & 437.04 & 452.10 & 451.76 \\
\cline { 2 - 10 }$\Delta_{X}$ & & -5.31 & -9.08 & 0.50 & -1.96 & 2.72 & -2.00 & 13.05 & 12.71 \\
& & $(4.80)$ & $(5.45)$ & $(9.01)$ & $(9.36)$ & $(3.96)$ & $(4.45)$ & $(6.96)$ & $(6.98)$ \\
$\Delta_{S}$ & 18.05 & 23.36 & 27.13 & 17.55 & 20.00 & 15.33 & 20.05 & 5.00 & 5.34 \\
& $(5.78)$ & $(6.50)$ & $(6.45)$ & $(9.22)$ & $(9.57)$ & $(6.12)$ & $(6.34)$ & $(8.00)$ & $(7.84)$
\end{tabular}

\begin{tabular}{|c|c|c|c|c|c|c|c|c|c|}
\hline \multicolumn{10}{|c|}{ Covariates } \\
\hline Other & No & Yes & Yes & Yes & Yes & Yes & Yes & Yes & Yes \\
\hline German & No & No & Yes & No & Yes & No & Yes & No & Yes \\
\hline Origin & No & No & No & Yes & Yes & No & No & Yes & Yes \\
\hline \multicolumn{10}{|c|}{ Observations } \\
\hline$N$ & 1,180 & 1,180 & 1,180 & 1,180 & 1,180 & 1,146 & 1,152 & 1,042 & 1,057 \\
\hline$N_{C H E}$ & 824 & 824 & 824 & 824 & 824 & 790 & 797 & 688 & 702 \\
\hline$N_{D E U}$ & 356 & 356 & 356 & 356 & 356 & 356 & 355 & 354 & 355 \\
\hline
\end{tabular}

Note: Immigrants' children are born within the country of testing and have both parents born outside of the country. Instead of the main specification where the missing values are imputed based on median imputation within the school; I use ordered probit models based on all other variables in the model to predict first number of books at home, including the predicted number of books I again use an ordered probit regression iteratively for mothers' and then fathers' education, a probit regression for German spoken at home and am ordinary least squares regression for HISEI (rounding the predicted values to the next integer). (1) Unconditional gap; (2) to (5) BO adjustment: uses a twofold Blinder-Oaxaca decomposition based on (2) gender, age in month, educational level of parents, highest occupation of the parents and number of books at home; (3) adds German spoken at home; (4) uses (2) and country of origin; and (5) uses (2), (3), and (4); (6) to (9) Matching adjustment is performed by propensity score matching with Gaussian kernel and bandwidth 0.1 , the propensity score is estimated by logit regression on the same covariates as in the BO adjustment. All standard errors given in brackets, are simulated with 500 bootstrap replications.

Source: PISA 2009, own calculations. 


\section{Sample selection and covariate balance}

\section{C.1 Missing values}

First, I present the missing values, their imputations and the sample selection procedure. Next, I show the covariate balance before and after the matching and propensity scores over the common support.

Table C.1: READING TEST SCORES BY Missing VALUES

\begin{tabular}{|c|c|c|c|c|c|c|}
\hline \multirow[t]{2}{*}{ Variable } & \multicolumn{3}{|c|}{ Switzerland } & \multicolumn{3}{|c|}{ Germany } \\
\hline & All & $\begin{array}{l}\text { Without } \\
\text { missings }\end{array}$ & $\begin{array}{c}\text { Only } \\
\text { missings }\end{array}$ & All & $\begin{array}{l}\text { Without } \\
\text { missings }\end{array}$ & $\begin{array}{l}\text { Only } \\
\text { missings }\end{array}$ \\
\hline Reading test scores & $\begin{array}{l}457.09 \\
(87.52)\end{array}$ & $\begin{array}{l}473.28 \\
(86.74)\end{array}$ & $\begin{array}{l}424.60 \\
(79.85)\end{array}$ & $\begin{array}{l}439.05 \\
(95.95)\end{array}$ & $\begin{array}{l}471.91 \\
(88.47)\end{array}$ & $\begin{array}{l}415.93 \\
(94.28)\end{array}$ \\
\hline$N$ & 824 & 556 & 268 & 356 & 151 & 205 \\
\hline
\end{tabular}

Note: Switzerland refers to the German-speaking part only. Reading test score is the average of five plausible values. If information of the student where missing in any of the variables mother's or father's education, language spoken at home, number of books at home or highest occupational status of the parents.

Source: PISA 2009, own calculations.

Table C.2: Missing value CORRelations Matrix

\begin{tabular}{rrrrrrr}
\hline \hline \multirow{2}{*}{ Variables } & & \multicolumn{5}{c}{ Missing } \\
\cline { 3 - 7 } & Reading & Mother & Father & German & Books & HISEI \\
\hline Reading test scores & 1.000 & & & & & \\
Missing values in & & & & & & \\
Mother & -0.178 & 1.000 & & & & \\
Father & -0.138 & 0.491 & 1.000 & & & \\
German & -0.167 & -0.001 & -0.008 & 1.000 & & \\
Books & -0.131 & 0.066 & 0.023 & 0.043 & 1.000 & \\
HISEI & -0.147 & 0.155 & 0.224 & 0.082 & 0.105 & 1.000 \\
\hline \hline
\end{tabular}

Note: Switzerland refers to the German-speaking part only. Correlation matrix between missing value indicators and reading test scores.

Source: PISA 2009, own calculations. 
Table C.3: Number of Missing VAlues And imputations

\begin{tabular}{lrrrrrr}
\hline \hline \multirow{2}{*}{ Variables } & \multicolumn{2}{c}{ Migrants } & & \multicolumn{2}{c}{ Natives } \\
\cline { 2 - 3 } \cline { 6 - 7 } & CHE & DEU & & CHE & DEU \\
\hline Full sample & 824 & 356 & & 4,362 & 3,238 \\
\cline { 7 - 8 } Total & 50 & 109 & & 176 & 143 \\
Mother education (ISCED) & 67 & 89 & & 173 & 262 \\
Father education (ISCED) & & & & & & \\
German not spoken at home & 206 & 77 & & 105 & 97 \\
Books at home & 9 & 6 & & 40 & 40 \\
Highest occupation (HISEI) & 26 & 39 & & 36 & 115
\end{tabular}

Subsample: Unfavorable background

Total

Mother education (ISCED)

Father education (ISCED)

\begin{tabular}{rr}
212 & 57 \\
\hline 1 & 8 \\
1 & 6 \\
63 & 20 \\
2 & 2 \\
6 & 12
\end{tabular}

$\begin{array}{lrr}\text { German not spoken at home } & & \\ \text { Books at home } & 2 & 2 \\ \text { Highest occopation (HISEI) } & 6 & 12\end{array}$

Highest occupation (HISEI) $\quad 6 \quad 12$

\begin{tabular}{lrr}
\hline Subsample: Turkish & & \\
Total & 109 & 187 \\
\cline { 2 - 3 } Mother education (ISCED) & 9 & 64 \\
Father education (ISCED) & 12 & 49 \\
German not spoken at home & 29 & 39 \\
Books at home & 1 & 2 \\
Highest occupation (HISEI) & 6 & 19 \\
\hline
\end{tabular}

Note: Switzerland refers to the German-speaking part only. Western Europe includes Austria, France, Germany and Liechtenstein; Southern Europe includes Greece, Italy, Portugal, and Spain; Former Yugoslavia: Bosnia and Herzegovina, Croatia, FYR Montenegro and Serbia; Aussiedler includes Poland and former USSR and Another country represents a category in the PISA Questionnaire and includes parents originating from different areas. Imputed data based on school level median (including native students); German not spoken at home includes missing values.

Source: PISA 2009, own calculations. 
Table C.4: SAMPle SELECTION

\begin{tabular}{|c|c|c|c|c|}
\hline \multirow[t]{2}{*}{ Variables } & \multicolumn{2}{|c|}{ Migrants } & \multicolumn{2}{|c|}{ Natives } \\
\hline & $\mathrm{CHE}$ & DEU & $\mathrm{CHE}$ & DEU \\
\hline Observations (before selection) & 1,697 & 515 & 6,598 & 3,276 \\
\hline Dropped due to & & & & \\
\hline Gender & 1 & & 1 & \\
\hline Parents no education $(I S C E D=0)$ & & & 4 & 38 \\
\hline Non-German-speaking part & 812 & & 2,231 & \\
\hline Country of origin & & & & \\
\hline Albania & 23 & & & \\
\hline Aussielder & & 159 & & \\
\hline Western European & 37 & & & \\
\hline Observations (after selection) & 824 & 356 & 4,362 & 3,238 \\
\hline
\end{tabular}

Note: Switzerland refers to the German-speaking part only. Western Europe includes Austria, France, Germany and Liechtenstein; Aussiedler includes immigrants from Poland and former USSR. Imputed data based on school level median (including native students); German not spoken at home includes missing values. Source: PISA 2009, own calculations. 


\section{C.2 Covariate balance}

Table C.5: Covariate balance: Adjusting Swiss students to German students' Characteristics, Panel A ADJustments

\begin{tabular}{|c|c|c|c|c|c|c|}
\hline \multirow[t]{2}{*}{ Variables } & \multirow{2}{*}{$\frac{\text { Actual }}{\text { DEU }}$} & \multicolumn{4}{|c|}{ Adjusted CHE } & \multirow{2}{*}{$\frac{\text { Actual }}{\text { CHE }}$} \\
\hline & & $(1)$ & $(2)$ & $(3)$ & $(4)$ & \\
\hline Age (in months) & 189.71 & 189.70 & 189.74 & 189.69 & 189.77 & 189.83 \\
\hline Male & 0.52 & 0.53 & 0.53 & 0.55 & 0.54 & 0.51 \\
\hline \multicolumn{7}{|l|}{ Education mother (ISCED) } \\
\hline No education (0) & 0.20 & 0.15 & 0.15 & 0.18 & 0.18 & 0.06 \\
\hline Primary $(1,2)$ & 0.21 & 0.23 & 0.23 & 0.21 & 0.20 & 0.42 \\
\hline Secondary $(3,4)$ & 0.42 & 0.42 & 0.42 & 0.39 & 0.40 & 0.29 \\
\hline Tertiary $(5,6)$ & 0.17 & 0.20 & 0.20 & 0.22 & 0.22 & 0.23 \\
\hline \multicolumn{7}{|l|}{ Education father (ISCED) } \\
\hline No education (0) & 0.16 & 0.10 & 0.09 & 0.12 & 0.12 & 0.03 \\
\hline Primary $(1,2)$ & 0.17 & 0.19 & 0.19 & 0.16 & 0.16 & 0.36 \\
\hline Secondary $(3,4)$ & 0.41 & 0.43 & 0.44 & 0.42 & 0.44 & 0.30 \\
\hline Tertiary $(5,6)$ & 0.26 & 0.29 & 0.28 & 0.29 & 0.28 & 0.31 \\
\hline Highest occupation (HISEI) & 40.51 & 41.49 & 41.49 & 42.01 & 42.04 & 41.61 \\
\hline \multicolumn{7}{|l|}{ Books at home } \\
\hline $0-10$ & 0.31 & 0.30 & 0.29 & 0.31 & 0.30 & 0.29 \\
\hline $11-25$ & 0.21 & 0.22 & 0.22 & 0.22 & 0.22 & 0.26 \\
\hline $26-100$ & 0.28 & 0.28 & 0.29 & 0.29 & 0.30 & 0.29 \\
\hline $101-200$ & 0.12 & 0.11 & 0.11 & 0.11 & 0.11 & 0.09 \\
\hline $201-500$ & 0.05 & 0.06 & 0.05 & 0.05 & 0.04 & 0.05 \\
\hline More than 500 & 0.03 & 0.03 & 0.03 & 0.03 & 0.03 & 0.02 \\
\hline German spoken at home & 0.33 & - & 0.30 & - & 0.30 & 0.19 \\
\hline \multicolumn{7}{|l|}{ Country of origin } \\
\hline Southern Europe & 0.06 & - & - & 0.07 & 0.07 & 0.14 \\
\hline Yugoslavia & 0.07 & - & - & 0.09 & 0.09 & 0.48 \\
\hline Turkey & 0.53 & - & - & 0.45 & 0.44 & 0.13 \\
\hline Another origin & 0.29 & - & - & 0.34 & 0.34 & 0.16 \\
\hline Observations & 356 & & & & & 824 \\
\hline
\end{tabular}

Note: Switzerland refers to the German-speaking part only. Besides the age in month and the hisei the variables can be interpreted as percentage points of the immigrants children population in each country. Columns (1) to (4) correspond to the adjustments of Table 4.

Source: PISA 2009, own calculations. 
Table C.6: Covariate balance: Adjusting German students to Swiss students' characteristics, PANEL B ADJUSTMENTS

\begin{tabular}{|c|c|c|c|c|c|c|}
\hline \multirow[t]{2}{*}{ Variables } & \multirow{2}{*}{$\begin{array}{c}\text { Actual } \\
\text { CHE }\end{array}$} & \multicolumn{4}{|c|}{ Adjusted DEU } & \multirow{2}{*}{$\begin{array}{c}\text { Actual } \\
\text { DEU }\end{array}$} \\
\hline & & (1) & $(2)$ & $(3)$ & $(4)$ & \\
\hline Age (in months) & 189.83 & 189.76 & 189.87 & 189.88 & 189.94 & 189.71 \\
\hline Male & 0.51 & 0.53 & 0.53 & 0.53 & 0.53 & 0.52 \\
\hline \multicolumn{7}{|l|}{ Education mother (ISCED) } \\
\hline No education (0) & 0.06 & 0.08 & 0.08 & 0.12 & 0.12 & 0.20 \\
\hline Primary (1,2) & 0.42 & 0.31 & 0.31 & 0.29 & 0.29 & 0.21 \\
\hline Secondary $(3,4)$ & 0.29 & 0.34 & 0.34 & 0.30 & 0.30 & 0.42 \\
\hline Tertiary $(5,6)$ & 0.23 & 0.27 & 0.27 & 0.29 & 0.29 & 0.17 \\
\hline \multicolumn{7}{|l|}{ Education father (ISCED) } \\
\hline No education (0) & 0.03 & 0.04 & 0.04 & 0.06 & 0.06 & 0.16 \\
\hline Primary $(1,2)$ & 0.36 & 0.25 & 0.26 & 0.24 & 0.24 & 0.17 \\
\hline Secondary $(3,4)$ & 0.30 & 0.37 & 0.36 & 0.36 & 0.35 & 0.41 \\
\hline Tertiary $(5,6)$ & 0.31 & 0.34 & 0.33 & 0.34 & 0.34 & 0.26 \\
\hline Highest occupation (HISEI) & 41.61 & 42.81 & 42.42 & 43.88 & 44.28 & 40.51 \\
\hline \multicolumn{7}{|l|}{ Books at home } \\
\hline $0-10$ & 0.29 & 0.28 & 0.27 & 0.29 & 0.29 & 0.31 \\
\hline $11-25$ & 0.26 & 0.25 & 0.25 & 0.23 & 0.22 & 0.21 \\
\hline $26-100$ & 0.29 & 0.29 & 0.30 & 0.30 & 0.31 & 0.28 \\
\hline $101-200$ & 0.09 & 0.10 & 0.10 & 0.09 & 0.09 & 0.12 \\
\hline $201-500$ & 0.05 & 0.05 & 0.05 & 0.05 & 0.05 & 0.05 \\
\hline More than 500 & 0.02 & 0.02 & 0.03 & 0.03 & 0.03 & 0.03 \\
\hline German spoken at home & 0.19 & - & 0.23 & - & 0.26 & 0.33 \\
\hline \multicolumn{7}{|l|}{ Country of origin } \\
\hline Southern Europe & 0.14 & - & - & 0.14 & 0.15 & 0.06 \\
\hline Yugoslavia & 0.48 & - & - & 0.28 & 0.28 & 0.07 \\
\hline Turkey & 0.13 & - & - & 0.18 & 0.18 & 0.53 \\
\hline Another origin & 0.16 & - & - & 0.24 & 0.25 & 0.29 \\
\hline Observations & 824 & & & & & 356 \\
\hline
\end{tabular}

Note: Switzerland refers to the German-speaking part only. Besides the age in month and the hisei the variables can be interpreted as percentage points of the immigrants children population in each country. Columns (1) to (4) correspond to the adjustments of Table 4.

Source: PISA 2009, own calculations. 


\section{C.3 Common support}

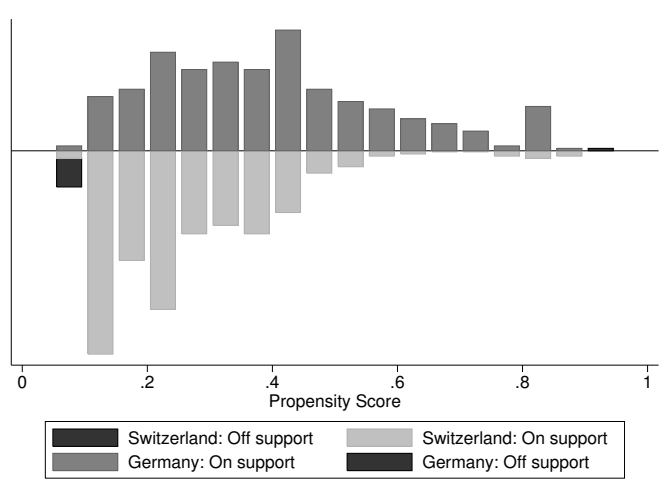

(1) Propensity score based on background characteristics

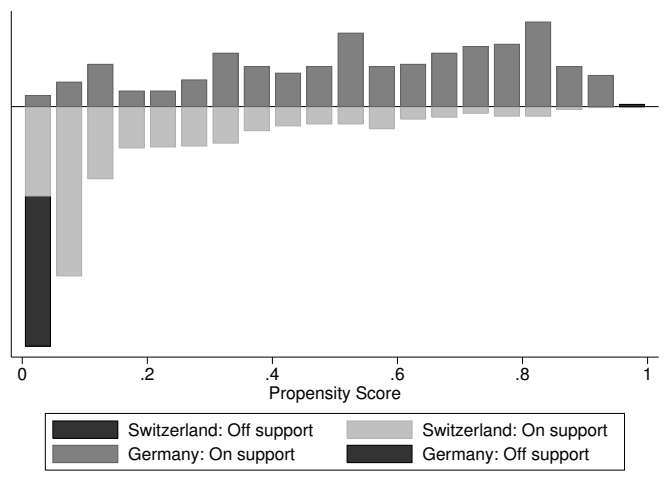

(3) Propensity score based on background characteristics and

country of origin

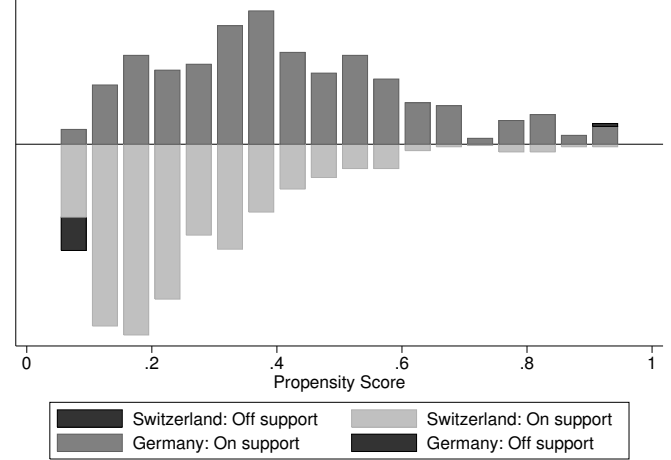

(2) Propensity score based on background characteristics and German spoken at home

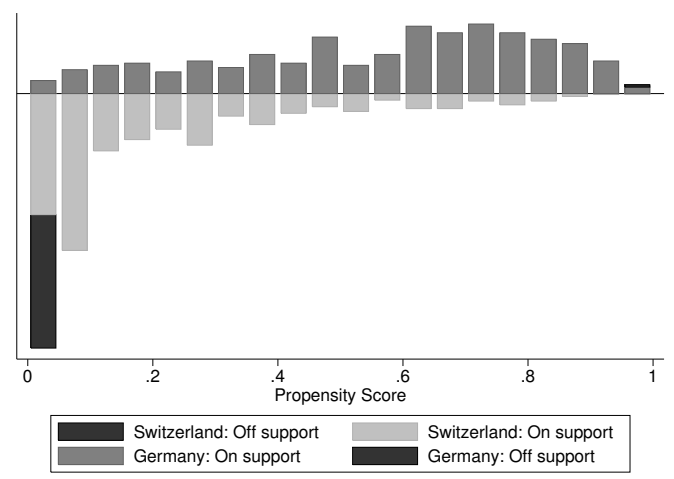

(4) Adjustment based on background characteristics, German spoken at home, and country of origin

Figure C.1: COMMON SUPPORT GRAPHS

Note: (1) Propensity scores are estimated on gender, age in months, educational level of parents, highest occupation of parents, and number of books at home; (2) Additionally uses German spoken at home; (3) uses parents' country of origin instead; (4) uses both German spoken at home and country of origin. Source: PISA 2009, own calculations 